\title{
Limiting the Accidental Pressure Drop in NIF Beam Tubes
}

\author{
M. Garcia
}

November 6, 2000

U.S. Department of Energy

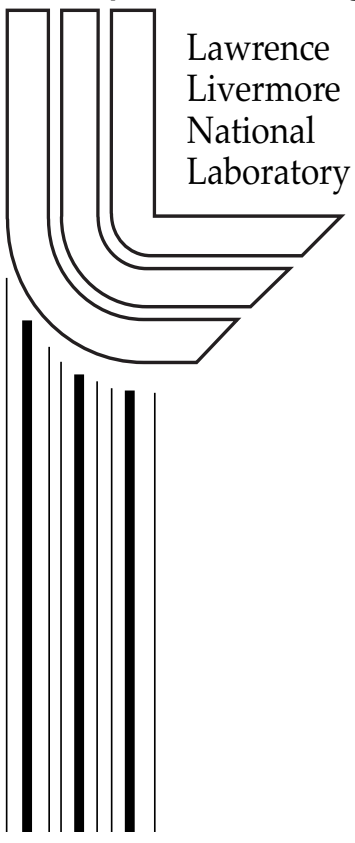




\section{DISCLAIMER}

This document was prepared as an account of work sponsored by an agency of the United States Government. Neither the United States Government nor the University of California nor any of their employees, makes any warranty, express or implied, or assumes any legal liability or responsibility for the accuracy, completeness, or usefulness of any information, apparatus, product, or process disclosed, or represents that its use would not infringe privately owned rights. Reference herein to any specific commercial product, process, or service by trade name, trademark, manufacturer, or otherwise, does not necessarily constitute or imply its endorsement, recommendation, or favoring by the United States Government or the University of California. The views and opinions of authors expressed herein do not necessarily state or reflect those of the United States Government or the University of California, and shall not be used for advertising or product endorsement purposes.

This work was performed under the auspices of the U. S. Department of Energy by the University of California, Lawrence Livermore National Laboratory under Contract No. W-7405-Eng-48.

This report has been reproduced directly from the best available copy.

Available electronically at http://www.doc.gov/bridge

Available for a processing fee to U.S. Department of Energy

And its contractors in paper from

U.S. Department of Energy

Office of Scientific and Technical Information

P.O. Box 62

Oak Ridge, TN 37831-0062

Telephone: (865) 576-8401

Facsimile: (865) 576-5728

E-mail: reports@adonis.osti.gov

Available for the sale to the public from

U.S. Department of Commerce

National Technical Information Service

5285 Port Royal Road

Springfield, VA 22161

Telephone: (800) 553-6847

Facsimile: (703) 605-6900

E-mail: orders@ntis.fedworld.gov

Online ordering: http://www.ntis.gov/ordering.htm

OR

Lawrence Livermore National Laboratory

Technical Information Department's Digital Library

http:/ / www.llnl.gov/tid/Library.html 


\title{
Limiting the accidental pressure drop in NIF beam tubes
}

\author{
Manuel Garcia \\ 6 November 2000
}

Lawrence Livermore National Laboratory, L-153, POB 808 Livermore, CA 94551-0808 USA garcia22@llnl.gov, (925) 422-6017, FAX (925) 423-5080

This report summarizes the use of a one-dimensional model of a time-dependent compressible flow condition to validate the results from a more sophisticated three-dimensional model. The flow conditions consist of the sudden decompression of a pressurized tube joined to an evacuated sphere, where the tube also has a leak to external atmosphere that is triggered open at a given pressure difference below sea-level pressure. This flow model is used to calculate conditions in a NIF beam tube if an internal vacuum barrier fails, and to calculate how the size and timing of an opening to external atmosphere changes tube pressure. Decompression of a NIF beam tube is a potential safety hazard since the tube could collapse if the tube pressure is reduced below the buckling limit. To prevent this from occurring, each pressurized section includes a rupture panel which is designed to open to external atmosphere at a given pressure difference. The inrush of external atmosphere through the rupture panel fills both the tube and the vacuum drawing on it, and in this way the pressure drop in the tube is quickly limited and reversed. In summary, the results from the $1 \mathrm{D}$ model indicate that the 3-D calculations are accurate and reasonable.

\section{Defining the problem}

The National Ignition Facility (NIF) is a laser fusion facility under construction at the Lawrence Livermore National Laboratory. NIF will have forty-eight tubes, each enclosing four laser beams, joined to an evacuated, ten meter diameter target chamber. Sections of the forty-eight tubes are slightly overpressurized with argon (1.028 $\mathrm{ATM}=15.1 \mathrm{psi}$ ), while other sections are evacuated. Should any diaphragm separating vacuum and gas burst then the decompression of the beam tube could lead to its collapse under the weight of external atmosphere, and this in turn could result in its separation and fall from the NIF framework. Some sections of the beam tube are 
vulnerable to collapse when the pressure drops more than 3 psi below ambient, while other sections buckle when the pressure drop is over 8 psi, see [1]. To prevent tube buckling induced by vacuum, rupture panels are built into the walls of pressurized sections, to act as leaks that trigger open at a given pressure difference and admit ambient air into the tube and the vacuum drawing on it. Figure 1 is a sketch of this idea.

An evacuated volume $V_{\mathrm{s}}$ drawing on a tube volume $V_{\mathrm{t}}$ initially pressurized to $O_{\mathrm{p}} p_{\mathrm{A}}$, where $O_{\mathrm{p}}$ is the pressure in atmospheres, and $p_{\mathrm{A}}$ $=14.696$ psia, which is one atmosphere in absolute psi, will equilibrate to a final pressure $p_{\mathrm{f}}$ given by

$$
\frac{p_{\mathrm{f}}}{p_{\mathrm{A}}}=\frac{V_{\mathrm{t}} O_{\mathrm{p}}}{V_{\mathrm{t}}+V_{\mathrm{s}}} .
$$

For $O_{\mathrm{p}}=1.028(15.1 \mathrm{psia}), V_{\mathrm{s}} / V_{\mathrm{t}}>0.292$ will draw tube pressure 3 psi below ambient (below 11.696 psia), and $V_{\mathrm{s}} / V_{\mathrm{t}}>1.256$ will draw tube pressure 8 psi below ambient (below 6.696 psia). If the rupture panel opens early in a decompression, say when tube pressure is within 2 psi below ambient, and the leak opening is sufficiently large, then external air can quickly rush in to fill the void and limit the pressure drop.

Three dimensional, time dependent calculations of specific NIF beam tube sections have been done with the ALE3D code, see [2]. In the ALE3D calculations, the rupture panel openings are coincident with the initiation of the decompressions at $t=0$. At present, it is not possible to have a triggered boundary condition in ALE3D. The work described in this report was performed to arrive at an independent confirmation of the ALE3D results. Independent confirmation of results is important to safety analysis. Also, the model described here includes the effect of delayed rupture panel opening, is easy to calculate (3 seconds on a Macintosh computer), and is a convenient way to see the effect of changes to any parameter. The model is described in the following sections, and results are compared with those of ALE3D.

Actual NIF situations are described in the section called "Comparison to ALE3D." Examples 1 through 6 prior to that are fictitious, they are constructed to illustrate various aspects of the physical model, and to produce graphically interesting pressure histories. 


\section{Unsteady 1D expansion}

In this model, pressurized volumes are taken to be cylinders of length $L$, diameter $d$, cross sectional area $A$, volume $V_{\mathrm{t}}$ and diaphragm area $A *$. Evacuated volumes are taken to be spheres of volume $V_{\mathrm{S}}$. The leak area $A_{\mathrm{L}}$ is the opening of the rupture panel in the tube wall triggered by a given $\Delta p=p_{\mathrm{A}}-p_{\mathrm{t}}\left(t_{\mathrm{L}}\right)$, where $p_{\mathrm{t}}\left(t_{\mathrm{L}}\right)$ is the appropriate tube pressure triggering the opening, which occurs at time $t_{\mathrm{L}}$.

The pressurized volume has an initial mass density of $\rho_{\mathrm{t}}(0)\left(\mathrm{kg} / \mathrm{m}^{-3}\right)$ of gas atoms (or molecules) of individual mass $m_{0}(\mathrm{~kg})$, ratio of specific heats $\gamma$, assumed constant (a perfect gas), and stored thermal energy $J$ (Joules). The initial total mass is $M_{\mathrm{t}}(0)=\rho_{\mathrm{t}}(0) V_{\mathrm{t}}(\mathrm{kg})$. The initial temperature of the gas, in degrees Kelvin $\left({ }^{\circ} \mathrm{K}\right)$, is

$$
T(0)=\frac{\gamma-1}{\gamma} \frac{m_{0}}{\mathrm{k}} \frac{J}{\rho_{\mathrm{t}}(0) V_{\mathrm{t}}},
$$

where $\mathrm{k}=1.38054 \times 10^{-23} \mathrm{Joule} /{ }^{\circ} \mathrm{K}$, Boltzmann's constant, and $\gamma=$ $5 / 3$ for atoms (like argon), and 7/5 for diatomic molecules (like "air"). The initial temperature was assumed to be $300{ }^{\circ} \mathrm{K}$ in the calculations shown in this report $\left(300{ }^{\circ} \mathrm{K}=26.8{ }^{\circ} \mathrm{C}=80.3{ }^{\circ} \mathrm{F}\right)$. The speed of sound in the gas is related to its temperature (at time $t$ ),

$$
c(t)=\sqrt{\gamma \frac{\mathrm{k} T(t)}{m_{0}}} .
$$

\section{Example 1}

A specific example follows, to help relate these concepts to the NIF situation. A tube with $L=65.5 \mathrm{~m}, d=2.571 \mathrm{~m}, O_{\mathrm{p}}=1.028 \mathrm{ATM}, m_{0}=$ $6.633 \times 10^{-26} \mathrm{~kg}(\operatorname{argon})$, and $T(0)=300{ }^{\circ} \mathrm{K}$, will have $V_{\mathrm{t}}=340 \mathrm{~m}^{3}, \rho_{\mathrm{t}}$ $=1.782 O_{\mathrm{p}}=1.832 \mathrm{~kg} / \mathrm{m}^{3}, M_{\mathrm{t}}(0)=623 \mathrm{~kg}, J=97.24 \mathrm{MJ}$, and $c=322.6$ $\mathrm{m} / \mathrm{s}$.

At the moment the diaphragm bursts, an expansion wave moves at the speed of sound into the tube, accelerating the gas behind it towards the new opening. As long as the pressure and density in the sphere are sufficiently low $\left(p_{\mathrm{s}} / p_{\mathrm{t}}<[1+(\gamma-1) / 2]-\gamma /(\gamma-1), 0.487\right.$ for $\gamma=$ $5 / 3$, and $\rho_{\mathrm{s}} / \rho_{\mathrm{t}}<[1+(\gamma-1) / 2]^{-1 /(\gamma-1)}, 0.650$ for $\left.\gamma=5 / 3\right)$, the mass 
flow rate $(\mathrm{kg} / \mathrm{s})$ through the diaphragm opening is 'choked,' that is to say sonic, and is given by

$$
\dot{m}_{\mathrm{t}}(t)=\sqrt{\left(\frac{2}{\gamma+1}\right)^{\frac{\gamma+1}{\gamma-1}}} \rho_{\mathrm{t}}(t) c(t) A * .
$$

On reaching the closed end of the tube, the expansion wave reflects, and now overtakes the outflowing gas. The gas behind the wave receding from the closed end is static, as gas cannot be sucked away from a wall to open a vacuum. However, the density in the tube has been reduced, because there is simply less total mass left to fill the tube volume. If the external vacuum is still sufficiently deep, then the expansion wave reflects at the diaphragm opening, and another cycle of expansion occurs. Figure 2 is a sketch of this unsteady one dimensional expansion. The motion and expansion of the gas are shown in Figure 2 by noting the shift in positions of five 'tracer' cross sections, labeled 1 through 5 .

In this model, the gas is assumed to be ideal $\left(p=\mathrm{k} \rho T / m_{0}\right)$, inviscid, and thermally isolated; it is an adiabatic perfect gas, and thus the flow is isentropic. In this case, $p_{\mathrm{t}} / \rho_{\mathrm{t}}^{\gamma}$ is constant $\left(=p_{\mathrm{t}}(0) / \rho_{\mathrm{t}}(0) \gamma\right)$, and

$$
\frac{p_{\mathrm{t}}(t)}{p_{\mathrm{t}}(0)}=\left(\frac{\rho_{\mathrm{t}}(t)}{\rho_{\mathrm{t}}(0)}\right)^{\gamma}=\left(\frac{T(t)}{T(0)}\right)^{\frac{\gamma}{\gamma-1}} .
$$

From (5) it is clear that the temperature of the gas remaining in the tube is lower than the initial temperature, $T(t)=T(0)\left[\rho_{\mathrm{t}}(t) / \rho_{\mathrm{t}}(0)\right]^{\gamma-1}$ (subscript $t$ is dropped for the temperature because the time variation for this quantity is only considered for gas within the tube). This means that the speed of sound is lower, and it takes longer for the expansion wave to complete an expansion cycle. Also, the choked mass flow rate is less because both $\rho_{\mathrm{t}}$ and $c$ are lower. If the expansion is into an infinite vacuum, then eventually $\rho_{\mathrm{t}}, T, c$, and mass flow rate simultaneously reach zero.

The time for a single expansion cycle is

$$
\Delta t(t)=\frac{2 L}{c(t)}
$$


which is time dependent because of expansion cooling. Let $i$ be an index of expansion cycles, then the mass in the tube at the end of cycle $i+1$ is

$$
\begin{aligned}
M_{\mathrm{t}}\left(t_{\mathrm{i}+1}=t_{\mathrm{i}}+\Delta t_{\mathrm{i}}\right) & =M_{\mathrm{t}}\left(t_{\mathrm{i}}\right)-\dot{m}_{\mathrm{t}}\left(t_{\mathrm{i}}\right) \Delta t_{\mathrm{i}} \\
& =M_{\mathrm{t}}\left(t_{\mathrm{i}}\right)-\sqrt{\left(\frac{2}{\gamma+1}\right)^{\frac{\gamma+1}{\gamma-1}}} \rho_{\mathrm{t}}\left(t_{\mathrm{i}}\right) A * 2 L,
\end{aligned}
$$

when the expansion is into a limitless void. The tube density at $t_{\mathrm{i}}$ is simply $M_{\mathrm{t}}\left(t_{\mathrm{i}}\right) / V_{\mathrm{t}}$. If the exhausted mass is thought of as being retrieved from this infinite void and accumulated in spherical volume $V_{\mathrm{s}}$, then the density in this sphere grows as

$$
\begin{aligned}
\rho_{\mathrm{S}}\left(t_{\mathrm{i}+1}=t_{\mathrm{i}}+\Delta t_{\mathrm{i}}\right) & =\rho_{\mathrm{S}}\left(t_{\mathrm{i}}\right)+\frac{\dot{m}_{\mathrm{t}}\left(t_{\mathrm{i}}\right) \Delta t_{\mathrm{i}}}{V_{\mathrm{S}}} \\
& =\rho_{\mathrm{S}}\left(t_{\mathrm{i}}\right)+\frac{\sqrt{\left(\frac{2}{\gamma+1}\right)^{\frac{\gamma+1}{\gamma-1}}} \rho_{\mathrm{t}}\left(t_{\mathrm{i}}\right) A * 2 L}{V_{\mathrm{s}}} .
\end{aligned}
$$

Clearly, for tube $V_{\mathrm{t}}$ connected to sphere $V_{\mathrm{s}}$, flow cannot continue once the falling tube density meets the rising sphere density, more on this in the next section.

\section{Example 2}

The normalized tube density for Example 1 with a diaphragm opening of $A *=0.159 \mathrm{~m}^{2}$, as inferred from (7) for thirty three expansion cycles, is shown in Figure 3 (\# vs. s). Each diamond corresponds to an expansion cycle. The lower curve in Figure 3 is the normalized density accumulation of the mass exhausted into a spherical volume of $V_{\mathrm{s}}=743 \mathrm{~m}^{3}$. Here, $\rho_{\mathrm{f}} / \rho_{\mathrm{t}}(0)=0.314$, as shown by the horizontal line. The tube and sphere densities meet at $\rho$ f near $t=$ 16 s. This example is labeled "Tube into void into sphere" in Figure 3 because as yet no account has been taken of the effect of rising sphere density limiting the flow rate from the tube.

To reiterate this last point, the two curves in Figure 3 have no physical connection, they are independent mathematical constructs that happen to intersect at a common value at $t=16 \mathrm{~s}$. The next section describes the additional physics required in order to have the evolution of the curves in Figure 3 affect each other. Once this 
additional physics is included, the curves will merge beyond $t=16 \mathrm{~s}$ without any slope discontinuity into a horizontal line at 0.314 in Figure 3.

\section{Pressure change dependent mass flow rate}

The mass flow rate through an area minimum depends on the change in pressure from conditions upstream to those downstream. A mass flow rate function that accounts for this effect is derived in this section. In the final result, the ratio of downstream to upstream density is used, which can be related to a pressure ratio by (5).

The Bernoulli's equation (integral of the momentum equation) for the compressible flow of an isentropic perfect gas (from the tube) is

$$
\frac{\gamma}{\gamma-1} \frac{p_{\mathrm{t}}(t)}{\rho_{\mathrm{t}}(t)}\left(\frac{p_{\star}(t)}{p_{\mathrm{t}}(t)}\right)^{\frac{\gamma-1}{\gamma}}+\frac{V^{2}}{2}=\frac{\gamma}{\gamma-1} \frac{p_{\mathrm{t}}(t)}{\rho_{\mathrm{t}}(t)},
$$

where $v$ is the speed of the gas at the diaphragm opening, and $p_{*}$ is the pressure there.

Both $p \star$ and $\rho \star$ are dummy variables - placeholders. They indicate conditions at any throat, here at either the burst diaphragm $A *$, or the triggered leak $A_{\mathrm{L}}$. For any throat, actual values for $p_{*}$ and $\rho *$ depend on the ratio of downstream to upstream conditions, and this discussion follows.

It is necessary to assume that the change in tube density $\rho_{\mathrm{t}}(t)$ and pressure $p_{\mathrm{t}}(t)$ during any single expansion cycle is relatively small $(\Delta \rho / \rho<1)$, in order to arrive at (9). This result is usually derived by assuming a steady flow with an infinite, unchanging, upstream reservoir. Equation (9) is a reasonable characterization for volumes that require many wave cycles to empty. More will be said about emptying time in the section called "steady isentropic expansion."

Using (5) in (9), the speed at the diaphragm is found to be

$$
V=\sqrt{\frac{2 \gamma}{\gamma-1} \frac{p_{\mathrm{t}}(t)}{\rho_{\mathrm{t}}(t)}\left[1-\left(\frac{\rho_{\star}(t)}{\rho_{\mathrm{t}}(t)}\right)^{\gamma-1}\right]} .
$$


Using (10) and the perfect gas law, the pressure change dependent mass flow rate at the diaphragm is found to be

$$
\dot{m}_{\mathrm{t}}\left(t, \frac{\rho_{\star}(t)}{\rho_{\mathrm{t}}(t)}\right)=\sqrt{\frac{2 \gamma}{\gamma-1} \frac{\mathrm{k} T(t)}{m_{0}}} \rho_{\mathrm{t}}(t) A *\left(\frac{\rho_{\star}(t)}{\rho_{\mathrm{t}}(t)}\right) \sqrt{1-\left(\frac{\rho_{\star}(t)}{\rho_{\mathrm{t}}(t)}\right)^{\gamma-1}} .
$$

This mass flow rate depends on both the time history of the upstream conditions, $\rho_{\mathrm{t}}(t)$ and $T(t)$, and the density at area $A *$, which is taken to be the same density as in the receiving volume $\left(\rho_{*}=\rho_{\mathrm{S}}\right.$ for receiving volume $V_{\mathrm{s}}$ ), subject to conditions described immediately following.

The mass flow rate is choked if the density in receiving volume $V_{\mathrm{s}}$ is low so that $\rho_{\mathrm{S}}(t)<\rho_{\mathrm{t}}(t)[1+(\gamma-1) / 2]^{-1 /(\gamma-1)}$. When this occurs, $V$ is a local speed of sound, the throat is at Mach one, the density at the throat is limited as follows,

$$
\frac{\rho_{\star}}{\rho_{\mathrm{t}}}=\left(1+\frac{\gamma-1}{2}\right)^{\frac{-1}{\gamma-1}},
$$

and the mass flow rate is at the maximum allowed for the upstream conditions, as given in (4). If the density in the receiving volume is above the limit set by (12), so that $\rho_{\mathrm{s}}(t)>\rho_{\mathrm{t}}(t)[1+(\gamma-1) / 2]^{-1 /(\gamma-1)}$, then the ratio $\rho_{\mathrm{s}}(t) / \rho_{\mathrm{t}}(t)$ influences the magnitude of the mass flow rate, as shown in (11) (by $\rho * / \rho_{\mathrm{t}}$ ). Figure 4 shows how the density ratio affects the mass flow rate. The vertical line in Figure 4 occurs at the limit set by (12), which is $\rho^{*} / \rho_{\mathrm{t}}=0.650$ for $\gamma=5 / 3$. Below this density ratio $d m_{\mathrm{t}} / d t=0.325[2 /(\gamma-1)]^{1 / 2} c \rho_{\mathrm{t}} A *$ for $\gamma=5 / 3$. The horizontal line in Figure 4 occurs at 0.325.

\section{Mass flow rate of triggered leak}

The model described here assumes that all gas has the same $\gamma$, whether that gas was initially within the tube or part of the external atmosphere. The mass flow rate of the triggered leak will have the form shown in equation (11), with constant upstream conditions $p_{\mathrm{A}}$, $\rho_{\mathrm{A}}$, and $T(0)$. The leak area density is conditional, specifically $\rho^{\star}=\rho_{\mathrm{t}}$, for $\rho_{\mathrm{t}}(t)>\rho_{\mathrm{A}}[1+(\gamma-1) / 2]^{-1 /(\gamma-1)}$, or $\rho^{\star}=\rho_{\mathrm{A}}[1+(\gamma-1) / 2]-1 /(\gamma-1)$, for $\rho_{\mathrm{t}}(t)<\rho_{\mathrm{A}}[1+(\gamma-1) / 2]^{-1 /(\gamma-1)}$. An additional factor to the leak mass flow rate function is a unit step function $U$ that triggers when the 
pressure difference across the tube wall exceeds a given limit $\Delta p$. This 'actuator function' can be stated as $U\left(p_{\mathrm{A}}-p_{\mathrm{t}}(t)-\Delta p\right)$, which is one if its argument is zero or positive, and zero otherwise. The mass flow rate for the triggered leak can be stated as follows

$$
\begin{aligned}
& \dot{m}_{\mathrm{L}}\left(t, \frac{\rho_{\star}(t)}{\rho_{\mathrm{A}}}\right)= \\
& \quad \sqrt{\frac{2}{\gamma-1}} c(0) \rho_{\mathrm{A}} A_{\mathrm{L}}\left(\frac{\rho_{\star}(t)}{\rho_{\mathrm{A}}}\right) \sqrt{1-\left(\frac{\rho_{\star}(t)}{\rho_{\mathrm{A}}}\right)^{\gamma-1}} U\left(p_{\mathrm{A}}-p_{\mathrm{t}}(t)-\Delta p\right) .
\end{aligned}
$$

The speed of gas flow through the leak area is

$$
V_{\mathrm{L}}=\sqrt{\frac{2 \gamma}{\gamma-1} \frac{p_{\mathrm{A}}}{\rho_{\mathrm{A}}}\left[1-\left(\frac{\rho_{\star}(t)}{\rho_{\mathrm{A}}}\right)^{\gamma-1}\right]} U\left(p_{\mathrm{A}}-p_{\mathrm{t}}(t)-\Delta p\right) .
$$

Recall that $\rho *$ is conditional, which affects (13) and (14) as was the case with (10) and (11). It is also convenient to remember that $\left(\gamma p_{\mathrm{A}} / \rho_{\mathrm{A}}\right)^{1 / 2}=c(0)$ as this factor appears in (14), and that pressure in function $U$ is related to density by $(5), p_{\mathrm{t}}(t) / p_{\mathrm{t}}(0)=\left[\rho_{\mathrm{t}}(t) / \rho_{\mathrm{t}}(0)\right] \gamma$.

\section{Coupled mass balance}

The mass in the tube at the end of wave cycle $i+1$ is given by

$$
M_{\mathrm{t}}\left(t_{\mathrm{i}+1}=t_{\mathrm{i}}+\Delta t_{\mathrm{i}}\right)=M_{\mathrm{t}}\left(t_{\mathrm{i}}\right)-\dot{m}_{\mathrm{t}}\left(t_{\mathrm{i}}, \frac{\rho_{\mathrm{s}}\left(t_{\mathrm{i}}\right)}{\rho_{\mathrm{t}}\left(t_{\mathrm{i}}\right)}\right) \Delta t_{\mathrm{i}}+\dot{m}_{\mathrm{L}}\left(t_{\mathrm{i}}, \frac{\rho_{\mathrm{t}}\left(t_{\mathrm{i}}\right)}{\rho_{\mathrm{A}}}\right) \Delta t_{\mathrm{i}}
$$

where the mass flow rates of equations (11) and (13) are used. The mass accumulated in the sphere is

$$
M_{\mathrm{S}}\left(t_{\mathrm{i}+1}=t_{\mathrm{i}}+\Delta t_{\mathrm{i}}\right)=M_{\mathrm{S}}\left(t_{\mathrm{i}}\right)+\dot{m}_{\mathrm{t}}\left(t_{\mathrm{i}}, \frac{\rho_{\mathrm{S}}\left(t_{\mathrm{i}}\right)}{\rho_{\mathrm{t}}\left(t_{\mathrm{i}}\right)}\right) \Delta t_{\mathrm{i}}
$$

These recursion relations are coupled $\left[\rho_{\mathrm{t}}\left(t_{\mathrm{i}}\right)=M_{\mathrm{t}}\left(t_{\mathrm{i}}\right) / V_{\mathrm{t}}\right.$ and $\rho_{\mathrm{s}}\left(t_{\mathrm{i}}\right)=$ $\left.M_{\mathrm{s}}\left(t_{\mathrm{i}}\right) / V_{\mathrm{s}}\right]$ by the pressure change dependent mass flow rates, and must be solved simultaneously. Remember that the density ratios $\rho_{\mathrm{s}} / \rho_{\mathrm{t}}$ and $\rho_{\mathrm{t}} / \rho_{\mathrm{A}}$, in $d m_{\mathrm{t}} / d t$ and $d m_{\mathrm{L}} / d t$ respectively, trigger conditional statements that determine the densities at throats $A *$ and 
$A_{\mathrm{L}}$, which are both labeled $\rho *$ in mass flow rate equations (11) and (13).

Example 3

A rupture panel of area $A_{\mathrm{L}}=0.159 \mathrm{~m}^{2}$ and trigger pressure difference $\Delta p=9$ psi is activated by the impulsive decompression of its tube for the coupled volumes described in Examples 1 and 2. This is a very small, stiff panel compared to the actual ones used on NIF, which have $A_{\mathrm{L}}=0.6 \mathrm{~m}^{2}$ and $\Delta p \approx 1 \mathrm{psi}$. The initial mass flow rate at the diaphragm is $m_{\mathrm{t}}(0)=52.87 \mathrm{~kg} / \mathrm{s}$, and the initial mass flow rate of the delayed leak into the tube is $m_{\mathrm{L}}\left(t_{\mathrm{L}}=8.1\right)=51.43 \mathrm{~kg} / \mathrm{s}$. Figure 5 shows the normalized densities of the tube and sphere volumes for this example (\# vs. s). Note that normalized ambient density is at $1 / 1.028=0.973$ in the figure, because the normalization is with respect to the initial tube density. Figure 6 shows the mass history of this example (kg vs. $\mathrm{s}$ ). Before the leak opens at $t_{\mathrm{L}}=8.1 \mathrm{~s}$, the total mass within the combined tube and sphere volumes is $623 \mathrm{~kg}$. By $t=$ $45 \mathrm{~s}$ a total of $1930 \mathrm{~kg}$ fills the combined volumes with a uniform density equal to that of the external atmosphere. In this case the tube loses mass because it initially had a pressure above ambient. Figure 7 shows the coupled pressure histories of the tube and sphere for this case (psi vs. s). Figure 8 shows the mass flow rate histories for this example (kg/s vs. s). The delay of leak opening is evident. Initially, the leak flow is choked for several seconds ('flat' in the graph), then it becomes subsonic in response to the rising pressure in the sphere. Figure 9 shows the velocity at the leak for this example (m/s vs. s). To convert this speed from $\mathrm{m} / \mathrm{s}$ to $\mathrm{kph}$, multiply by 3.6; to convert from m/s to mph, multiply by 2.2369363 . The choking of this flow is evident by the 'flat top' in the graph just after leak opening. Figure 10 shows the leak area pressure history for this example (psi vs. s). On opening, the leak flow is choked and the pressure at $A_{\mathrm{L}}$ is stalled at $p_{\mathrm{L}}=p_{\mathrm{A}}[1+(\gamma-1) / 2]-\gamma /(\gamma-1)=0.487 p_{\mathrm{A}}$ $=7.159$ psi. Once the tube fills sufficiently, the leak mass flow becomes subsonic, and the tube and leak area pressures coincide. Figure 11 shows the temperature of the tube gas for this example in Fahrenheit degrees [Fahrenheit $=(9 / 5)($ Kelvin -273.159$)+32],\left({ }^{\circ} \mathrm{F}\right.$ vs. s). Figure 12 shows how expansion cycle time interval, equation (6), varies during the flow (s vs. s).

Example 4 
This case is identical to Example 3 but with the leak triggering open at $\Delta p=0$ psi, which occurs when the tube pressure has dropped from 15.1 psi to 14.696 psi. Figure 13 shows the coupled pressure histories (psi vs. s). It is evident that the early opening of the leak area has limited the drop in tube pressure. Figure 14 shows the mass flow rate histories, the leak has no delay and is never choked (kg/s vs. s). Figure 15 shows the velocity at the leak area, which has a broad maximum at approximately $170 \mathrm{~m} / \mathrm{s}(612 \mathrm{kph}$ or 380 $\mathrm{mph}$ ) for about $10 \mathrm{~s}$ duration. Figure $\mathbf{1 6}$ shows the tube and leak area pressure histories, which are coincident.

\section{Steady isentropic expansion}

An intrinsically unsteady decompression is one in which a significant fraction of the mass exhausts during a wave cycle. This is more likely to be the case when the pressurized volume has a compact shape and a relatively large discharge area - such as an explosion. The accidental decompression of NIF beam tubes, as characterized by Examples 1 through 4, is a steady process, conditions change slowly in comparison to wave cycle time intervals. The wave cycle, mass balance analysis is most convenient in that the calculation of coupled, linear, algebraic recursion relations is both robust and rapid when compared to the numerical calculation of the differential equations of fluid flow. Of course, the physical model embodied in the recursion equations cannot have the refinement of the differential description (equations of Euler or Navier-Stokes), which becomes essential in analyzing unsteady flow with gradients. It is useful to have an indicator that signals whether a proposed decompression is likely to be steady or unsteady. This indicator is the 'emptying time' $\tau$, and it is described in this section.

Consider the steady decompression of volume $V_{\mathrm{t}}$ exhausting through area $A *$ into an infinite void. The rate of change of the source volume density $\rho_{\mathrm{t}}(t)$ is

$$
\frac{d \rho_{\mathrm{t}}(t)}{d t}=-\frac{\dot{m}_{\mathrm{t}}}{V_{\mathrm{t}}}=-\frac{\rho_{*} C_{*} A_{*}}{V_{\mathrm{t}}}=-\left(\frac{\rho_{\mathrm{t}}(t)}{\left(1+\frac{\gamma-1}{2}\right)^{\frac{1}{\gamma-1}}}\right)\left(\frac{c(t)}{\sqrt{1+\frac{\gamma-1}{2}}}\right) \frac{A_{\star}}{V_{\mathrm{t}}} .
$$

By assumption the source volume equilibrates quickly to changing conditions, and it is always uniform. The temperature and density at 
time $t$ in the source volume are related to initial conditions $T(0)$ and $\rho_{\mathrm{t}}(0)$ by (5); applying this within $c(t)$ in equation (17) leads to

$$
\begin{aligned}
& \frac{d \rho_{\mathrm{t}}(t)}{d t}=-\left(\frac{2}{\gamma+1}\right)^{\frac{1}{2}\left(\frac{\gamma+1}{\gamma-1}\right)} \frac{\rho_{\mathrm{t}} c A *}{V_{\mathrm{t}}} \\
& \left.=-\left(\frac{2}{\gamma+1}\right)^{\frac{1}{2}} \frac{\gamma+1}{\gamma-1}\right) \frac{\rho_{\mathrm{t}}(0) c(0) A_{*}}{V_{\mathrm{t}}}\left(\frac{\rho_{\mathrm{t}}(t)}{\rho_{\mathrm{t}}(0)}\right)^{\left(\frac{\gamma+1}{2}\right)},
\end{aligned}
$$

and this integrates to

$$
\frac{\rho_{\mathrm{t}}(t)}{\rho_{\mathrm{t}}(0)}=\left(\frac{1}{1+\frac{t}{\tau}}\right)^{\frac{2}{\gamma-1}}
$$

where

$$
\tau=\frac{V_{\mathrm{t}}}{C(0) A_{*}}\left(\frac{2}{\gamma-1}\right) \sqrt{\left(\frac{\gamma+1}{2}\right)^{\frac{\gamma+1}{\gamma-1}}} .
$$

The equation for the temperature follows from (5)

$$
\frac{T(t)}{T(0)}=\left(\frac{1}{1+\frac{t}{\tau}}\right)^{2} .
$$

The characteristic time $\tau$ is the emptying time of the pressurized volume. This time is defined by two parameters: the initial speed of sound $c(0)$, and a characteristic length defined by the ratio of volume $V_{\mathrm{t}}$ to discharge area $A_{*}$. This 'depth' can be quite different from the actual length scale $L$ of the volume - for vanishing $A *$ the depth becomes infinite for any volume, it takes forever to empty a tank through a closed area. Therefore, a steady decompression occurs when

$$
\frac{L A *}{V_{\mathrm{t}}} \ll\left(\frac{1}{\gamma-1}\right) \sqrt{\left(\frac{\gamma+1}{2}\right)^{\frac{\gamma+1}{\gamma-1}}}
$$


because the wave cycle time is much smaller than the emptying time, $\Delta t<\tau$. The volume can then equilibrate to a uniform density $\rho_{\mathrm{t}}(t)$ at each moment. An alternate interpretation is that a volume $V_{\mathrm{t}}$ with length scale $L$, determining the wave cycle time, can only decompress in a steady fashion if the discharge area is limited so that $A_{*} \ll\left(V_{\mathrm{t}} / L\right)(\gamma-1)^{-1}[(\gamma+1) / 2](\gamma+1) /[2(\gamma-1)]$.

\section{Example 5}

For the case described in the previous four examples, $\tau=35.4 \mathrm{~s}$ (compare to $\Delta t(0)=0.41 \mathrm{~s}), V_{\mathrm{t}} / A_{*}=2138 \mathrm{~m}$, (compare to $\left.L=65.5 \mathrm{~m}\right)$, and the upper limit of $A$ * for steady flow is $2.667 V_{\mathrm{t}} / L=13.85 \mathrm{~m}^{2}$ (compare to $A^{*}=0.159 \mathrm{~m}^{2}$ ). The density and temperature histories from equations (19) and (21) exactly match their counterparts from the recursion equation calculation, prior to the opening of the rupture panel (e.g., Figures 3 and 11).

It is possible to invert $p_{\mathrm{t}}(t)$ to $t\left(p_{\mathrm{t}}\right)$, and to use this as a predictor of rupture panel opening time $t_{\mathrm{L}}$. Using (5) in (19) with $p_{\mathrm{t}}\left(t_{\mathrm{L}}\right)=p_{\mathrm{A}}-\Delta p$,

$$
t_{\mathrm{L}}=\tau\left[\left(\frac{p_{\mathrm{t}}(0)}{p_{\mathrm{A}}-\Delta p}\right)^{\frac{\gamma-1}{2 \gamma}}-1\right] .
$$

Notice the form of equation (23), it takes an infinite time to reach a final pressure of zero, and it takes zero time to reach a final pressure equal to the initial pressure.

\section{Example 6}

The leak trigger time for Example 5 with $\Delta p=9$ psi is found from (23) to be $t_{\mathrm{L}}=7.63 \mathrm{~s}$, which is within one wave cycle interval $\Delta t$ of the initiation time of $8.1 \mathrm{~s}$ observed in the recursion equation calculation described in Example 3. When $\Delta p=0 \mathrm{psi}, t_{\mathrm{L}}=0.2 \mathrm{~s}$.

Reference [3] was used as the primary source for compressible flow formulas [e.g., (3), (5), (9)] in this report. An earlier description of the emptying time model appeared in [4].

\section{Heat transfer}

Is it possible that heat can flow from the surroundings into a NIF beam tube cooled by decompression, and thus keep the pressure 
higher than expected from the adiabatic model? The adiabatic assumption is jeopardized if heat can diffuse across the beam tube radius in a time short compared to the emptying time. This diffusion time can be estimated as

$$
\tau_{\mathrm{K}}=\frac{r^{2}}{\chi}=\frac{\rho C_{\mathrm{p}}}{K} r^{2},
$$

where $r$ is the tube radius, $K$ is the thermal conductivity $\left[\mathrm{J} /\left({ }^{\circ} \mathrm{K} \mathrm{m} \mathrm{s}\right)\right]$, $\chi$ is the thermometric conductivity $\left(\mathrm{m}^{2} / \mathrm{s}\right), \rho$ is the mass density, and $C_{\mathrm{p}}$ is the specific heat at constant pressure, see [5]. For argon at sealevel temperature and pressure, estimates of $K, \chi$, and $\tau_{\mathrm{K}}$ across one meter are: $K \approx 0.02 \mathrm{~J} /\left({ }^{\circ} \mathrm{K} \mathrm{m} \mathrm{s}\right), \chi \approx 2 \times 10^{-5} \mathrm{~m}^{2} / \mathrm{s}, \tau_{\mathrm{K}}=1 / \chi \approx 4 \times 10^{4} \mathrm{~s}$. It seems unlikely that heat flow will affect the course of NIF beam tube decompressions, during their emptying times they are adiabatic.

\section{Comparison to ALE3D}

The volumes and initial conditions used in Examples 1 through 6 correspond to those of a beam tube decompressing into the NIF target sphere as calculated by T. Reitter with ALE3D, however $A_{\mathrm{L}}$ and $A *$ were different, see [2]. In Reitter's memo, this example is labeled "target area (failure of FOA)," and in his calculation $A_{\mathrm{L}}=0.6 \mathrm{~m}^{2}$ (instead of 0.159 ) and $A *=0.18 \mathrm{~m}^{2}$ (instead of 0.159). Reitter notes that more recent information has the likely burst area at $A *=0.16$ $\mathrm{m}^{2}$, which was used in the previous examples (actually $0.45 \mathrm{~m}$ diameter for $0.159 \mathrm{~m}^{2}$ area). Minimum tube pressure with $\Delta p=0 \mathrm{psi}$, $A^{*}=0.18 \mathrm{~m}^{2}$, and $A_{\mathrm{L}}=0.6 \mathrm{~m}^{2}$ for this particular case ("FOA") from ALE3D and the present analysis compare as follows.

Table 1: Minimum tube pressures compared for FOA

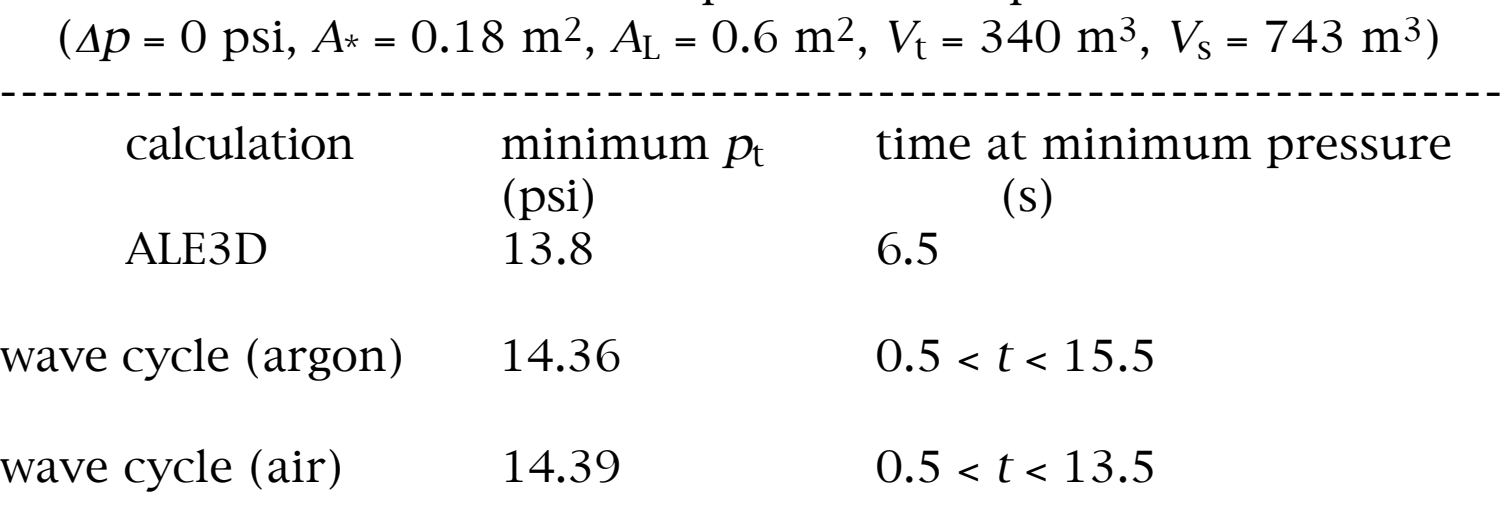


The lower minimum pressure in the ALE3D calculation is probably a result of the inclusion of real geometry. Also, frictional effects rob pressure at the expense of mass flow rate, so the leak fills the tube more slowly than anticipated by the wave cycle model.

The other two cases calculated with ALE3D are labeled by their burst diaphragms, SF4 and SF1, see [2]. The burst diaphragm areas used in these ALE3D calculations, as well as here, were $A *=0.16 \mathrm{~m}^{2}$. Comparisons to wave cycle results are shown in Tables 2 and 3, respectively.

Table 2: Minimum tube pressures compared for SF4 $\left(\Delta p=0\right.$ psi, $\left.A^{*}=0.16 \mathrm{~m}^{2}, A_{\mathrm{L}}=0.6 \mathrm{~m}^{2}, V_{\mathrm{t}}=340 \mathrm{~m}^{3}, V_{\mathrm{S}}=56.9 \mathrm{~m}^{3}\right)$

calculation minimum $p_{\mathrm{t}}$ (psi)

ALE3D time at minimum pressure

(s)

$\begin{array}{ccl}\text { ALE3D } & 14.3 & 3.5 \\ \text { wave cycle (argon) } & 14.4 & 0.5<t<2.0\end{array}$

The failure of SF4 evacuates the $65.5 \mathrm{~m}$ beam tube into a collimator (cones meeting at a minimum area) of smaller volume, and the throat of this collimator can influence the pace of decompression.

The failure of SF1 exhausts a small pressurized volume into an initially evacuated section of pipe. In this case the wave cycle intervals $(L=4.39 \mathrm{~m})$ are quite short, and as $A_{\mathrm{L}}$ and thus $d m_{\mathrm{L}} / d t$ are relatively large, the tube fills very quickly and the recursion solution oscillates about atmospheric pressure with each cycle of $\Delta t=2 L / c$. To overcome this problem, this case was recalculated with a modified time step $\Delta t=(2 L / c) A * /\left(A *+A_{\mathrm{L}}\right)$. Now, the problem advances smoothly in these smaller time steps from one set of averaged conditions to the next. Both the oscillating wave cycle $(\Delta t=2 \mathrm{~L} / \mathrm{C})$ and the modified cycle $[\Delta t=0.2105(2 L / c)]$ results are quoted in Table 3 . 
Table 3: Minimum tube pressures compared for SF1

\begin{tabular}{|c|c|c|}
\hline calculation & $\begin{array}{l}\underset{(p s i)}{\operatorname{minimum}} p_{\mathrm{t}} \\
\end{array}$ & $\begin{array}{l}\text { time at minimum pressure } \\
\text { (s) }\end{array}$ \\
\hline ALE3D & 12.5 & $1.0<t<2.0$ \\
\hline wave cycle (argon) & $14.7 \pm 1$ & $0<t<2.4$ (oscillations) \\
\hline modified cycle (arg & 14.4 & $0<t<1.8$ (smooth) \\
\hline
\end{tabular}

The ALE3D result for the SF1 case is 2 psi lower than the recursion model results, presumably an effect of the particular geometry of the decompressing enclosure. If $\Delta p$ is set at $2 p s i$ in the modified wave cycle model for SF1, the pressure almost immediately rises from 12.7 psi when the rupture panel $A_{\mathrm{L}}$ opens, to $14.4 \mathrm{psi}$ and remains there for most of the approximately 2 to 3 seconds filling of combined volumes $V_{\mathrm{t}}$ and $V_{\mathrm{s}}$. The small volume $V_{\mathrm{t}}$ is flooded with atmosphere through large rupture panel leak area $A_{\mathrm{L}}$, overwhelming the loss of mass through small area $A *$ to vacuum $V_{\mathrm{s}}$. The pressure at the burst diaphragm area $A *$ is about $7 \mathrm{psi}$ when flow there is choked. Clearly, there is an upstream region close to throat $A *$ in which the tube gas accelerates from its 'stagnation' pressure of over 14 psi at zero velocity, to sonic speed at the throat and $7 \mathrm{psi}$. The ALE3D result probably accounts for the geometry of such an acceleration zone, and the location of some ALE3D pressure sensors may be within this region. Also, it is possible that the entire volume $V_{\mathrm{t}}$ is a region of considerable flow between $A_{\mathrm{L}}$ and $A_{*}$, and the idea that a large fraction of $V_{t}$ is a reservoir of usually static gas (a cyclically revised average) between $A_{\mathrm{L}}$ and $A *$ is not accurate in this case.

The ALE3D result for SF1 is most probably a static pressure average of the entire flow between $A_{\mathrm{L}}$ and $A_{*}$. Pressure along the flow in a wind tunnel is measured by pressure taps, which are small holes in the tunnel wall connected by tubes to manometers, or electronic pressure sensors. If any such hole is too large, there is a pressure gradient across it, and the pressure measured at the far end of the tube is an average. The situation of SF1 can be seen as a grossly oversized wall pressure tap viewing the flow from $A_{\mathrm{L}}$ at atmospheric pressure, to choked $A *$, with the result that it measures an average 
value near 11 psi $[\approx(14.7+7.2) / 2]$. The geometry shown for the ALE3D model of the SF1 flow has $A_{\mathrm{L}}$ and $A *$ essentially across the diameter from each other at one end of closed tube $V_{\mathrm{t}}$, and the pressure of 12.5 psi quoted in Table 3 occurring at the far end of the tube from both $A_{\mathrm{L}}$ and $A *$.

The effect of varying the triggering pressure difference of the rupture panel in the case of FOA (Table 1 ) is shown in Table 4, but this time with $A_{*}=0.16 \mathrm{~m}^{2}$ (instead of 0.18 ). This table shows $\Delta p$, $p_{\mathrm{t}}\left(t_{\mathrm{L}}\right)=p_{\mathrm{A}}-\Delta p, t_{\mathrm{L}}$ from equation $(23)\left(p_{\mathrm{t}}(0)=15.11 \mathrm{psi}, \tau=35.35 \mathrm{~s}\right)$, the minimum tube pressure observed in the recursion calculation $\left(p_{\min }\right)$, the time of this minimum $\left(t_{\min }\right)$, and the time interval during which the tube pressure rides at a pressure plateau of 14.43 psi. All entries in Table 4 were calculated with a modified time step equal to $\Delta t=(2 L / c) A * /\left(A *+A_{\mathrm{L}}\right)=0.2105(2 L / c)$.

Table 4: Minimum FOA pressure for $\Delta p$

$$
\left(A *=0.16 \mathrm{~m}^{2}, A_{\mathrm{L}}=0.6 \mathrm{~m}^{2}, V_{\mathrm{t}}=340 \mathrm{~m}^{3}, V_{\mathrm{s}}=743 \mathrm{~m}^{3}\right)
$$

\begin{tabular}{|c|c|c|c|c|c|}
\hline $\begin{array}{l}\Delta p \\
(\mathrm{psi})\end{array}$ & $\begin{array}{l}p_{\mathrm{t}}\left(t_{\mathrm{L}}\right) \\
(\mathrm{psi})\end{array}$ & $\begin{array}{l}t_{\mathrm{L}} \\
(\mathrm{s})\end{array}$ & $\begin{array}{l}p_{\min } \\
(\mathrm{psi})\end{array}$ & $\begin{array}{l}t_{\min } \\
(\mathrm{s})\end{array}$ & $\begin{array}{c}14.43 \text { psi plateau } \\
\text { (s) }\end{array}$ \\
\hline 0.0 & 14.7 & 0.20 & 14.43 & - & $1.0-19$ \\
\hline 0.5 & 14.2 & 0.44 & 14.14 & 0.60 & $2.0-19$ \\
\hline 1.0 & 13.7 & 0.70 & 13.64 & 0.86 & $2.0-19$ \\
\hline 1.5 & 13.2 & 0.97 & 13.15 & 1.12 & $2.5-18.5$ \\
\hline 2.0 & 12.7 & 1.25 & 12.68 & 1.39 & $3.0-18.5$ \\
\hline 3.0 & 11.7 & 1.86 & 11.66 & 2.01 & $4.0-18.5$ \\
\hline 4.0 & 10.7 & 2.53 & 10.58 & 2.74 & $5.0-18.5$ \\
\hline 5.0 & 9.7 & 3.28 & 9.61 & 3.48 & $6.0-19$ \\
\hline 6.0 & 8.7 & 4.13 & 8.62 & 4.33 & $7.0-19$ \\
\hline 7.0 & 7.7 & 5.11 & 7.64 & 5.29 & $8.0-19.5$ \\
\hline 8.0 & 6.7 & 6.26 & 6.06 & 6.48 & $9.5-20$ \\
\hline 9.0 & 5.7 & 7.63 & 5.65 & 7.81 & 11. -21 \\
\hline 10 & 4.7 & 9.32 & 4.65 & 9.51 & 13. -22 \\
\hline
\end{tabular}

The pressure history of the FOA case at $\Delta p=2$ psi, in Table 4 , is shown in Figure 17 (psi vs. s). The shortened time steps are evident by comparing with Figure 7 . The overwhelming magnitude of the triggered leak flow is evident, the tube pressure quickly equilibrates 
to near atmospheric density while the sphere fills up. Figure 18 shows the mass flow rates for this FOA case (kg/s vs. s). The mass flow rate through burst diaphragm $A$ * initially chokes at $52.9 \mathrm{~kg} / \mathrm{s}$, while the mass flow rate through triggered leak $A_{\mathrm{L}}$ chokes at 194 $\mathrm{kg} / \mathrm{s}$. Notice that the mass flow through $A_{\mathrm{L}}$ is always subsonic (never choked) for FOA with $\Delta p=2$ psi. The velocity of the inrush at $A_{\mathrm{L}}$ for this case is shown in Figure 19 (m/s vs. s). At the moment the rupture panel opens the velocity achieves a peak of $133 \mathrm{~m} / \mathrm{s}=480$ $\mathrm{kph}=298 \mathrm{mph}$, however it quickly settles down to a sedate $47.5 \mathrm{~m} / \mathrm{s}$ $=171 \mathrm{kph}=106 \mathrm{mph}$ for about half of the $30 \mathrm{~s}$ event. Figure 20 shows the pressure at the leak area for this case, which coincides with the pressure in the tube from the moment of the opening of $A_{\mathrm{L}}$. Atmospheric pressure is indicated in Figure 20 by a thin horizontal line at $14.696 \mathrm{psi}$. The temperature of the gas in the tube plummets from $80.3^{\circ} \mathrm{F}$ to $40^{\circ} \mathrm{F}$ when $A_{\mathrm{L}}$ opens, then hovers near $67^{\circ} \mathrm{F}$ during most of the rest of the discharge, finally settling to $70^{\circ} \mathrm{F}$ at the end of the event.

\section{Conclusions}

The calculations by Reitter [2] seem quite accurate and reasonable.

When the rupture panel opening is significantly larger than the burst diaphragm $\left(A_{\mathrm{L}}>A *\right)$ then the minimum tube pressure is likely to be the pressure triggering the leak $p_{\mathrm{t}}\left(t_{\mathrm{L}}\right)=p_{\mathrm{A}}-\Delta p$, for the given $\Delta p$ of the panel. Recall that $p_{\mathrm{A}}=14.696$ psi.

If the length scale of the decompressing volume, either $L$ or $V_{\mathrm{t}}^{1 / 3}$ is comparable to the length scale of either nozzle area, $A_{\mathrm{L}}{ }^{1 / 2}$ or $A_{\star} 1 / 2$, then volume $V_{\mathrm{t}}$ is a relatively small region of significant flow between source $A_{\mathrm{L}}$ and sink $A *$. The geometry of the flow path determines the local pressure in this case, and ALE3D will be more accurate (possibly much more) than the model here.

In all real cases the geometry of the flow path influences, to some extent, the pressure observed at any location within a decompressing volume. Any difference in the pressure predictions by ALE3D and the model here for a specific case are most probably due to this effect. 


\section{Acknowledgment}

Tom Reitter was most helpful in explaining his calculations and generous in providing information on NIF beam tube geometry, which took some effort to compile.

This work was performed under the auspices of the U.S.

Department of Energy by the University of California, Lawrence Livermore National Laboratory under contract No. W-7405-Eng-48.

\section{References}

1 D. Trummer, "NIKE3D calculations of the interstage docking enclosure," 9 March 2000, as noted in [2].

2 T. Reitter, "Calculations of the effectiveness of a rupture panel for the various NIF enclosures," draft memo, 25 October 2000.

3 Equations, Tables, and Charts for Compressible Flow, NACA Report 1135, NASA Ames Research Staff, 1953

4 M. Garcia, "Self effect in expanding electron beam plasma," Lawrence Livermore National Laboratory, UCRL-ID-134375, 7 May 1999, also The 26th International Conference on Plasma Science, Monterey, CA USA, 20-24 June 1999, 2 P22.

5 L. D. Landau and E. M. Lifshitz, Fluid Mechanics, Reading MA: Addison-Wesley Publishing Co., 1959

\section{List of figures}

1 Decompression triggered leak

2 Unsteady $1 \mathrm{D}$ expansion

3 Tube into void into sphere

$4 \quad$ Mass flow rate at density ratio

$5 \quad$ Leak triggered at $\Delta p=9 \mathrm{psi}$ 
6 Mass history with 9 psi leak trigger

$7 \quad$ Pressure history with 9 psi leak trigger

8 Mass flow rate history at $\Delta p=9$ psi

9 Velocity at the leak with 9 psi trigger

10 Leak area pressure history (9 psi)

11 Temperature of tube gas (9 psi), ${ }^{\circ} \mathrm{F}$

12 Wave cycle time intervals (9 psi)

13 Pressure history with 0 psi leak trigger

14 Mass flow rate history at $\Delta p=0$ psi

15 Velocity at the leak with 0 psi trigger

16 Leak and tube pressure history (0 psi)

17 FOA pressure with $\Delta p=2$ psi

18 FOA mass flow rates with $\Delta p=2 \mathrm{psi}$

19 FOA leak velocity with $\Delta p=2$ psi

20 FOA leak area pressure with $\Delta p=2$ psi 


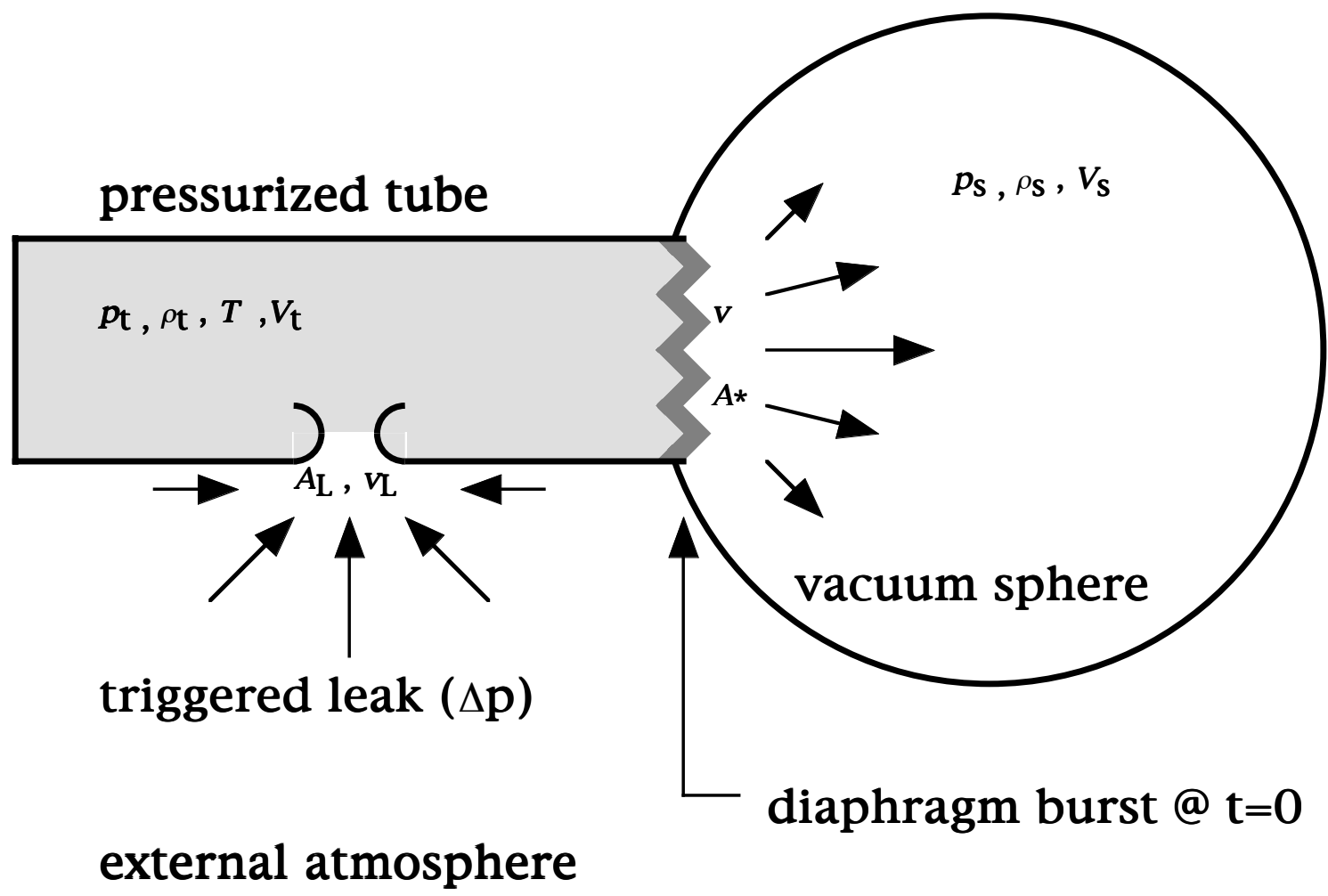

$p_{\mathrm{A}}, \rho \mathrm{A}, T(0)$

Figure 1, Decompression triggered leak 


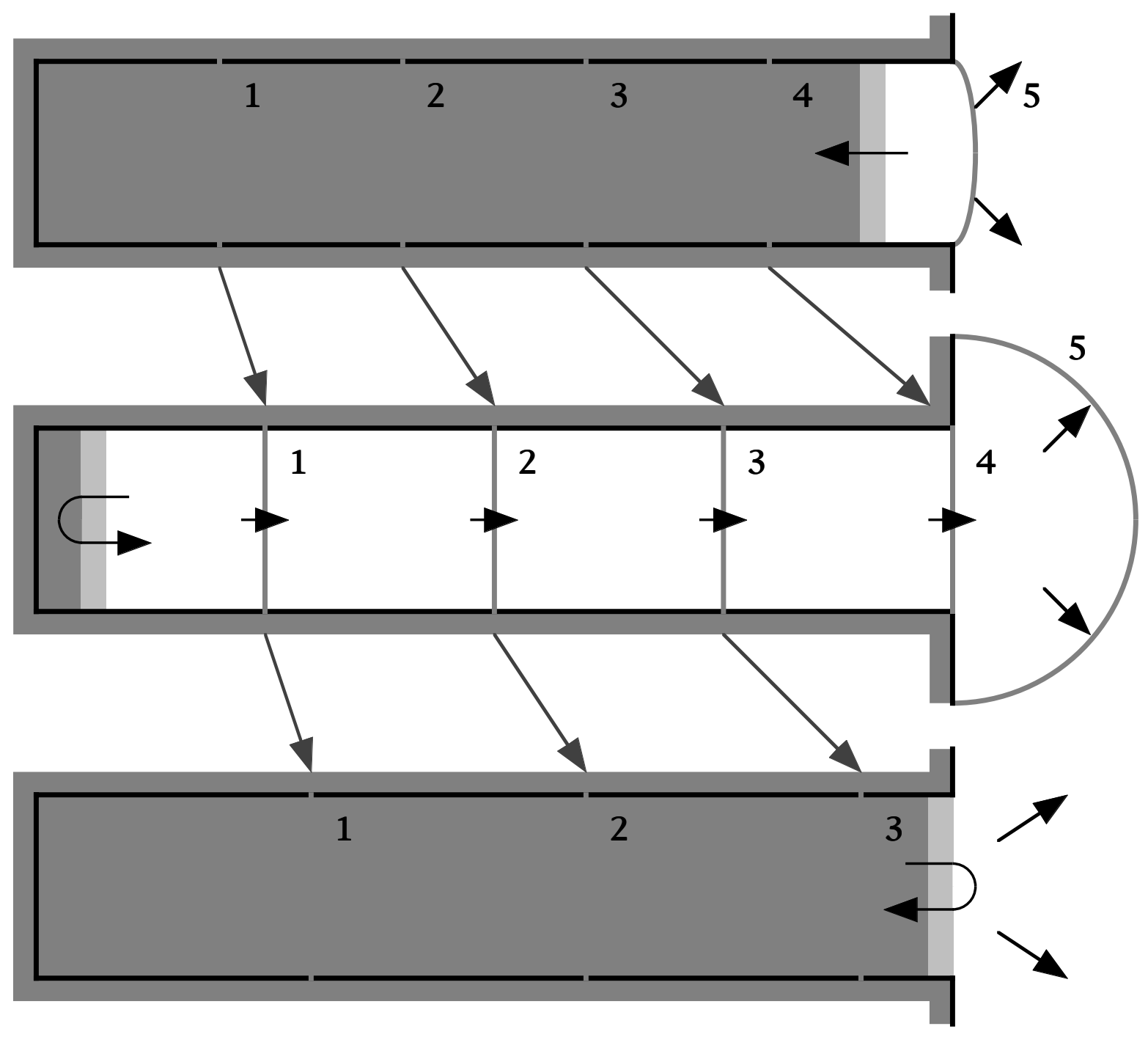

Figure 2, Unsteady 1D expansion 


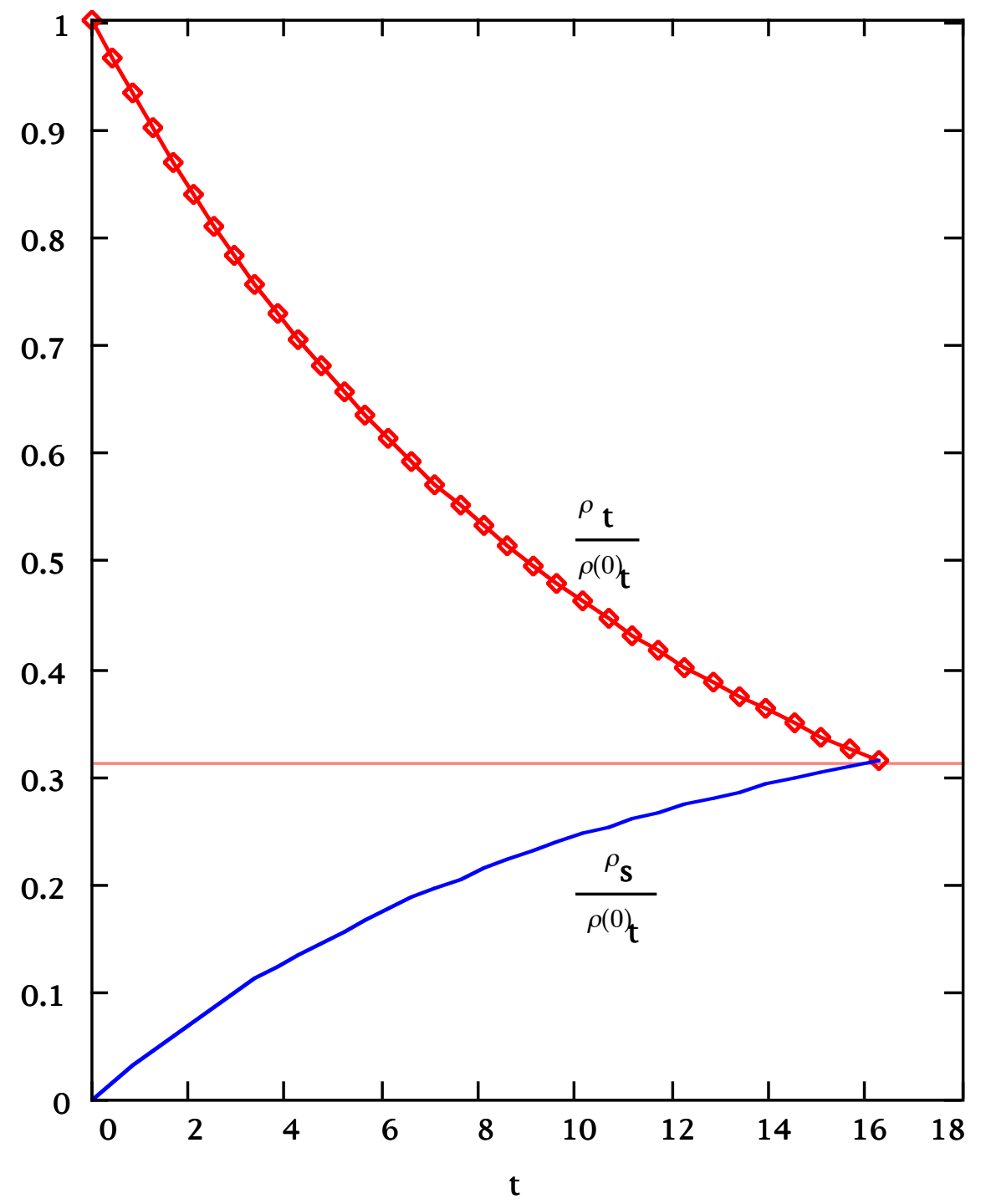

Figure 3, Tube into void into sphere 


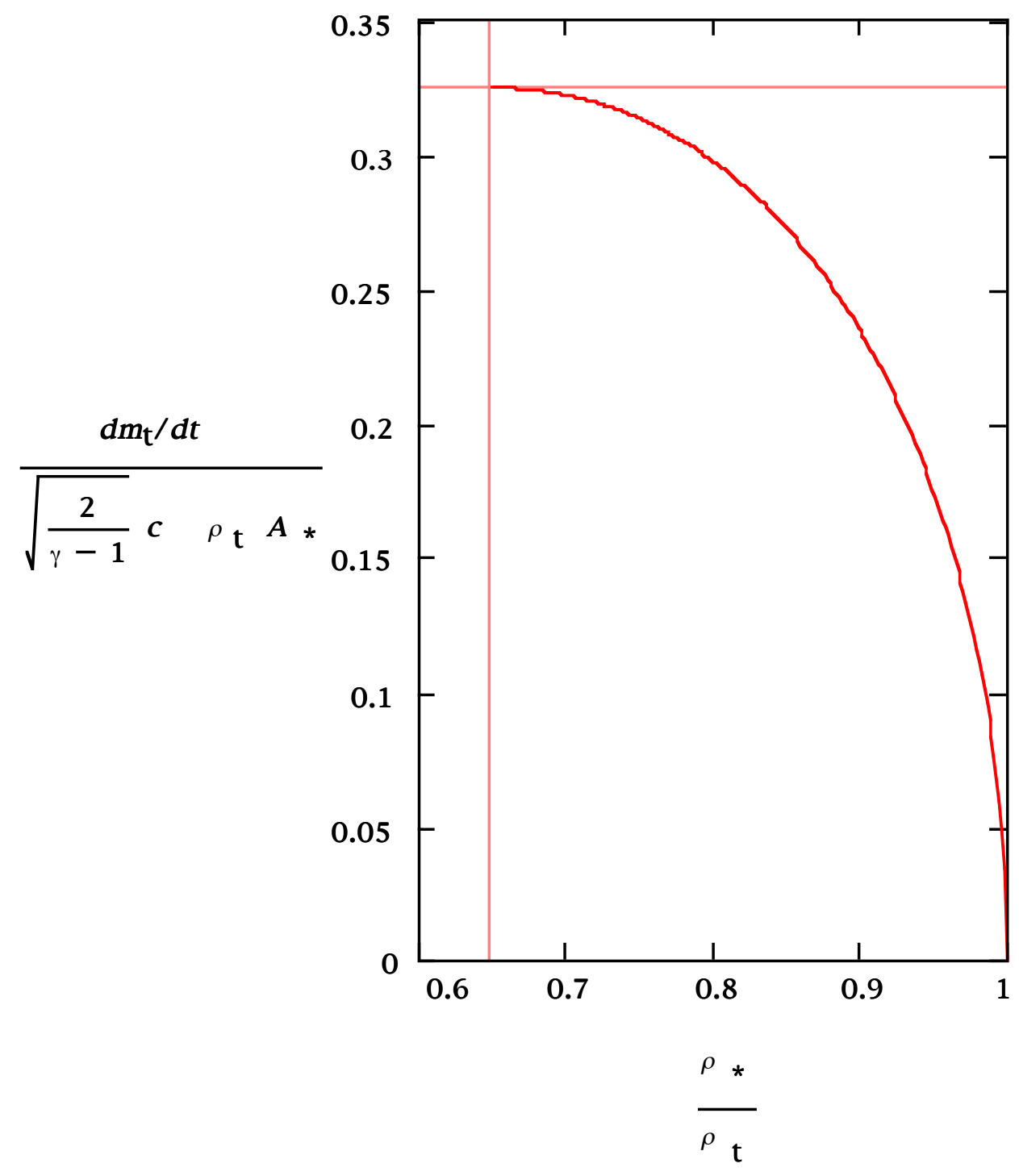

Figure 4, Mass flow rate at density ratio 


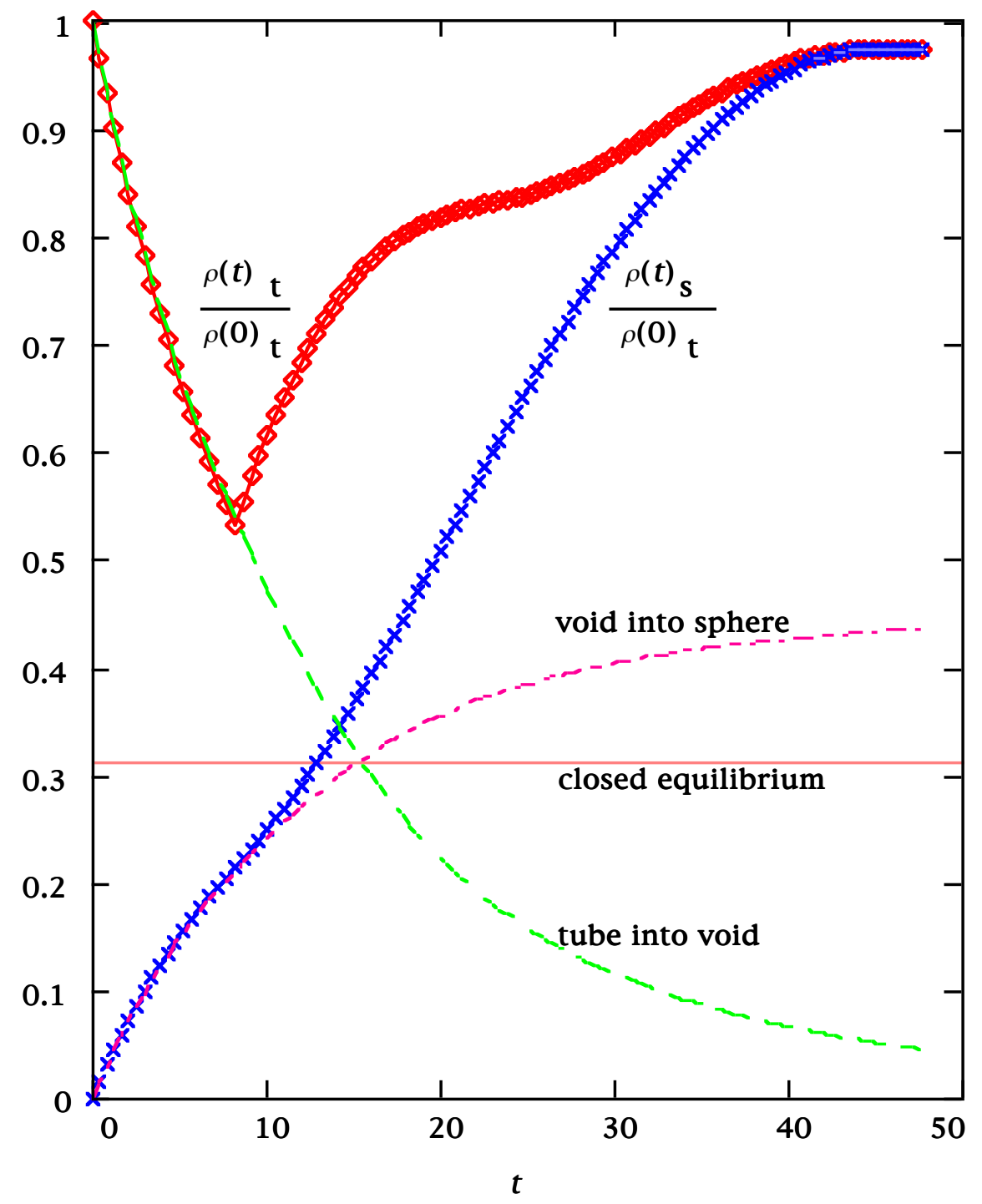

Figure 5, Leak triggered at $\Delta p=9 \mathrm{psi}$ 


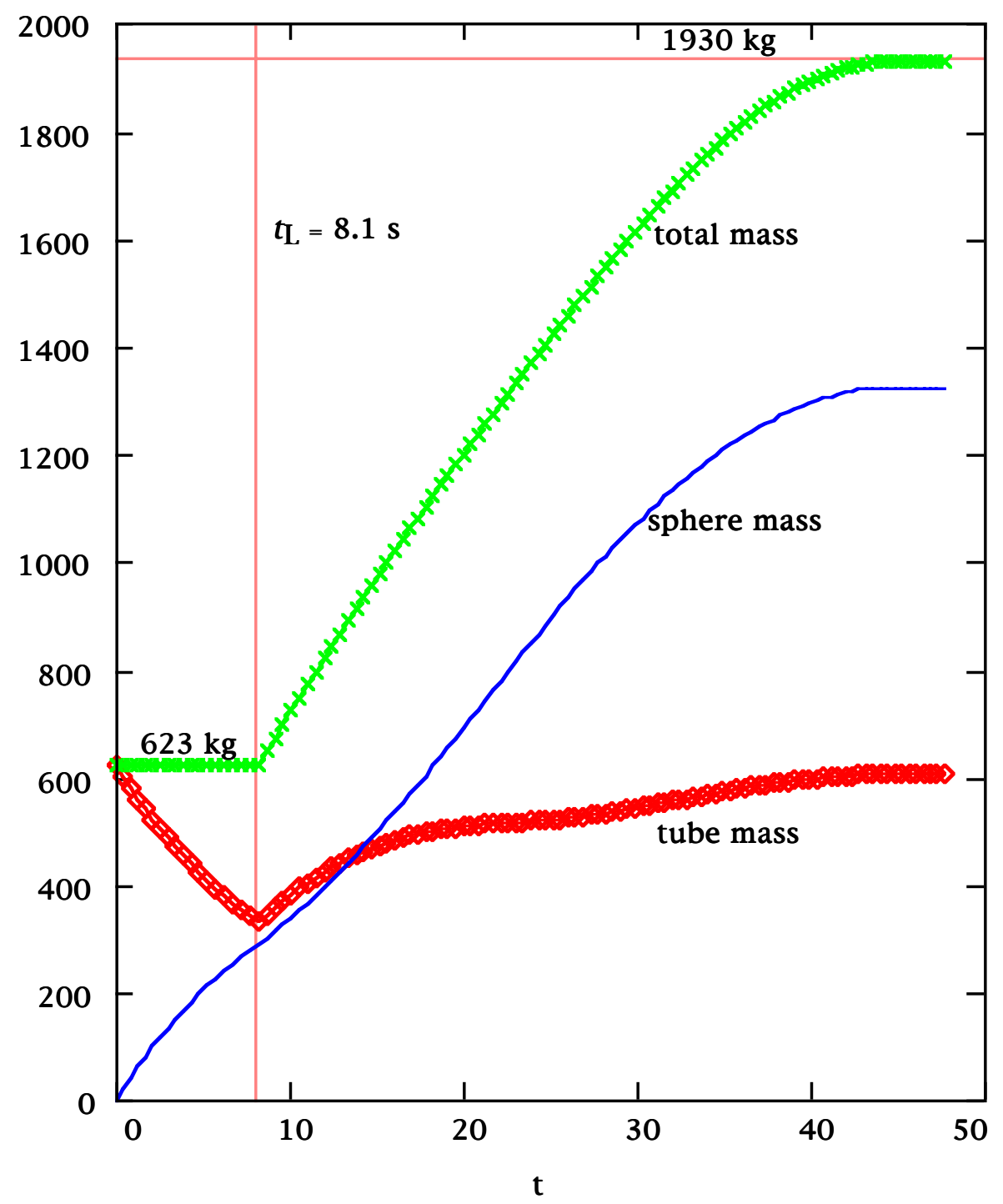

Figure 6, Mass history with 9 psi leak trigger 


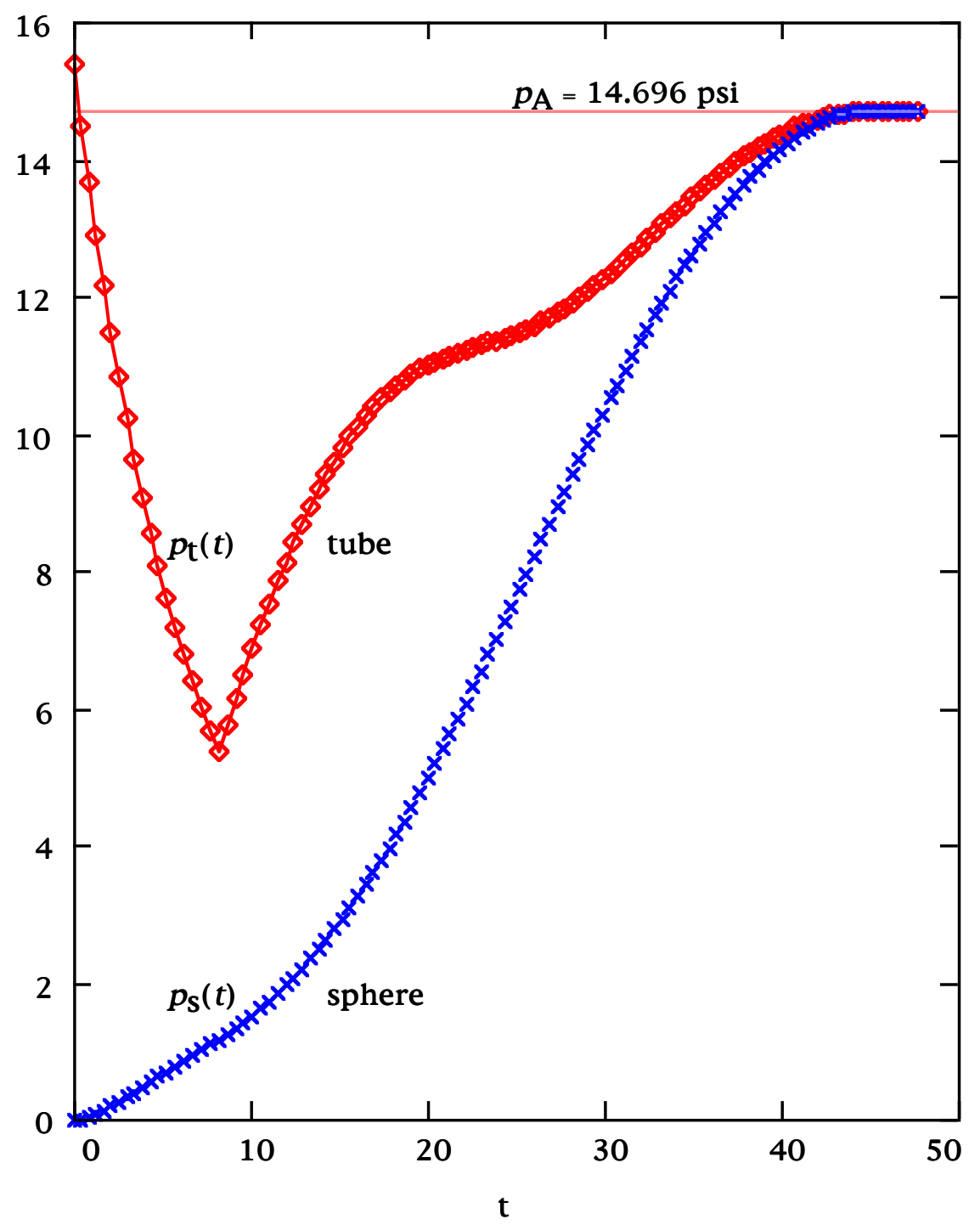

Figure 7, Pressure history with 9 psi leak trigger 


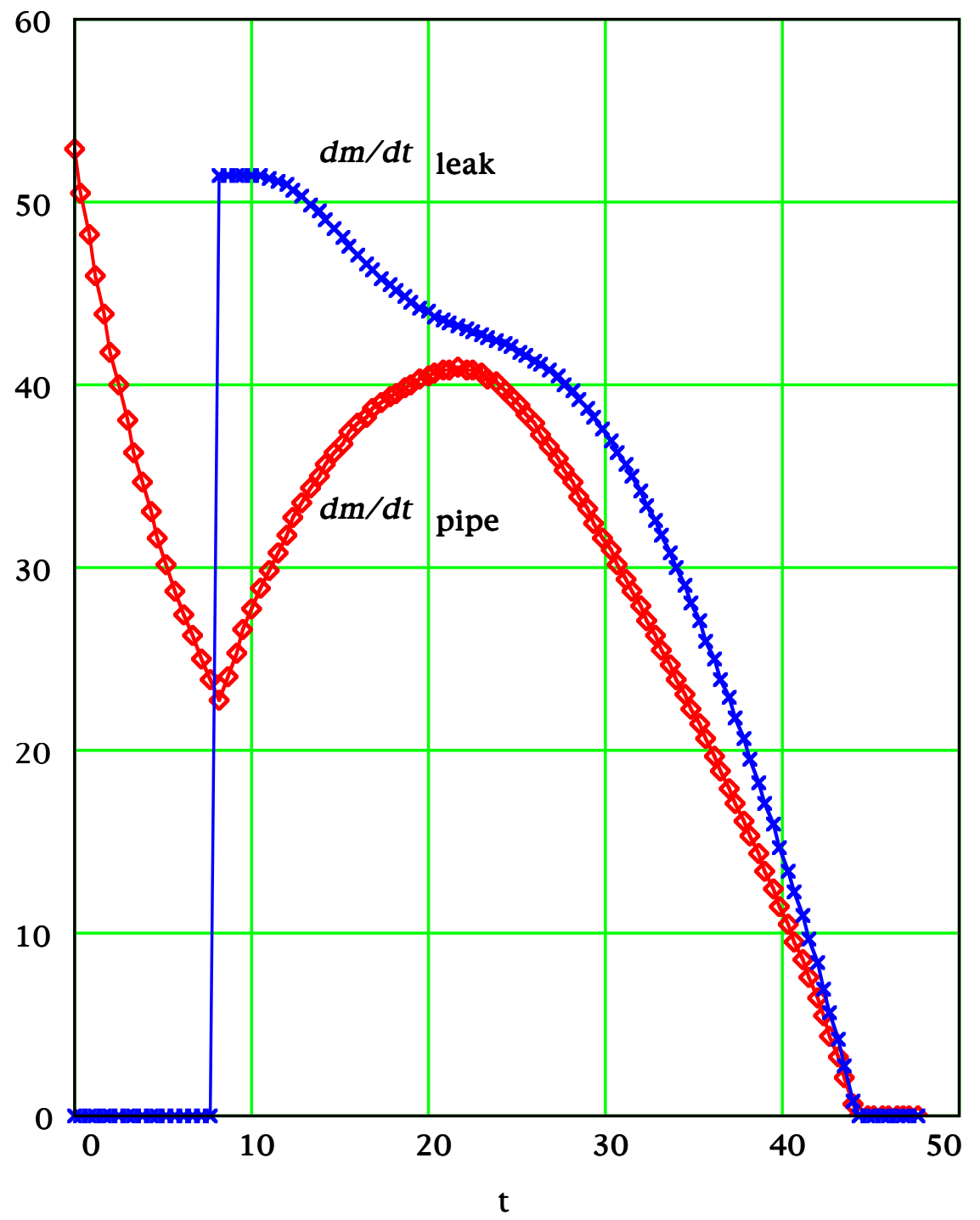

Figure 8 , Mass flow rate history at $\Delta p=9$ psi 


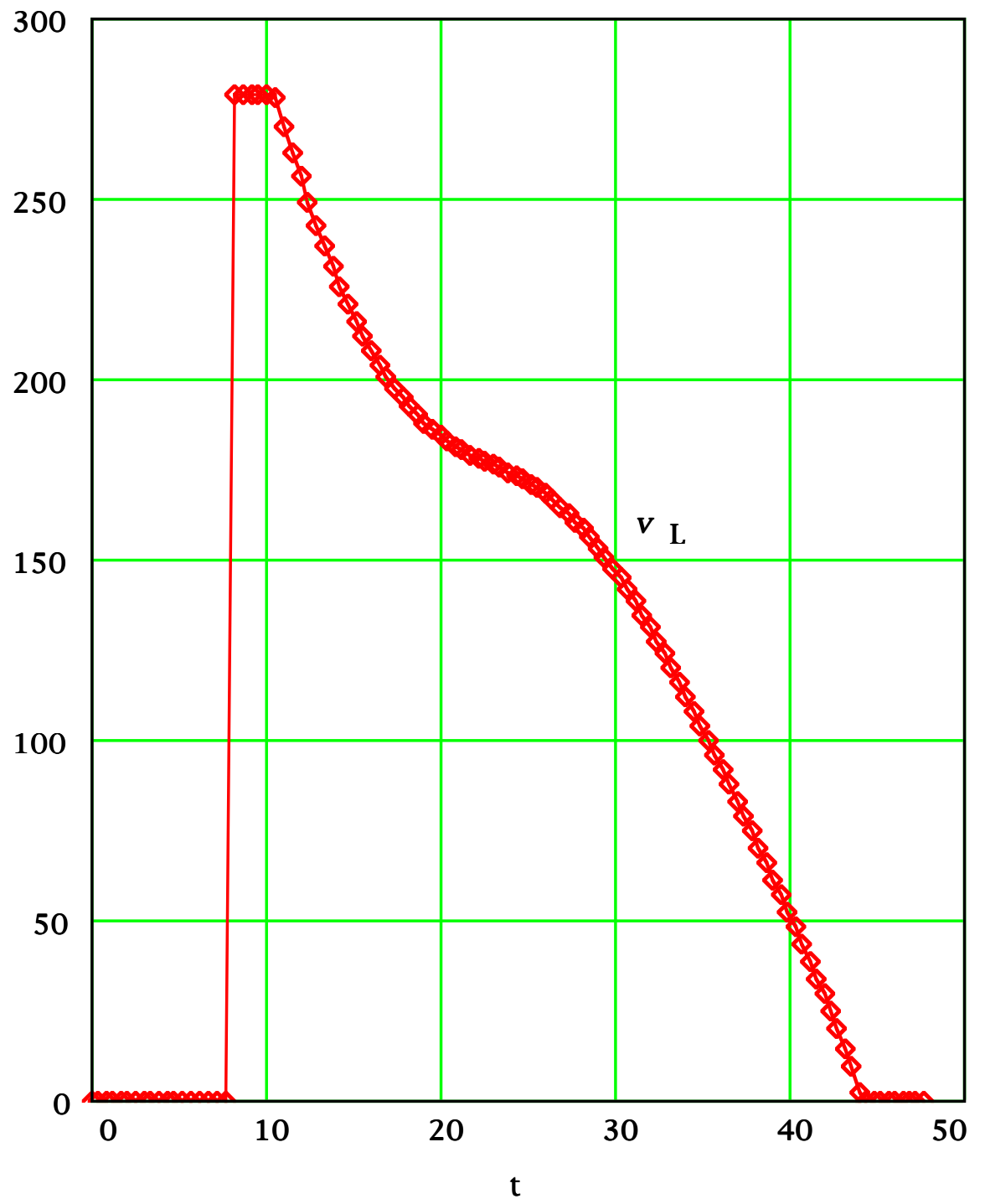

Figure 9, Velocity at the leak with 9 psi trigger 


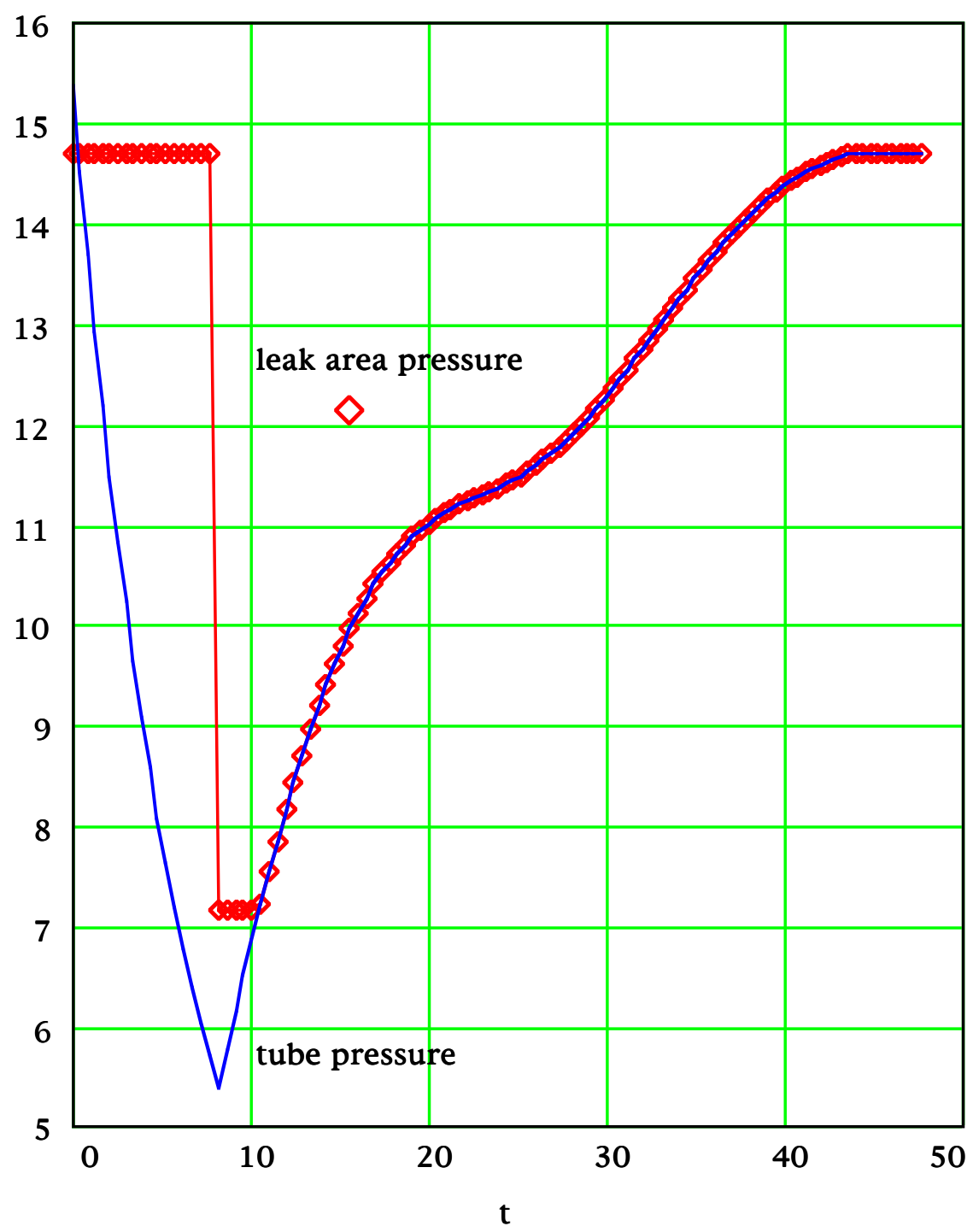

Figure 10, Leak area pressure history (9 psi) 


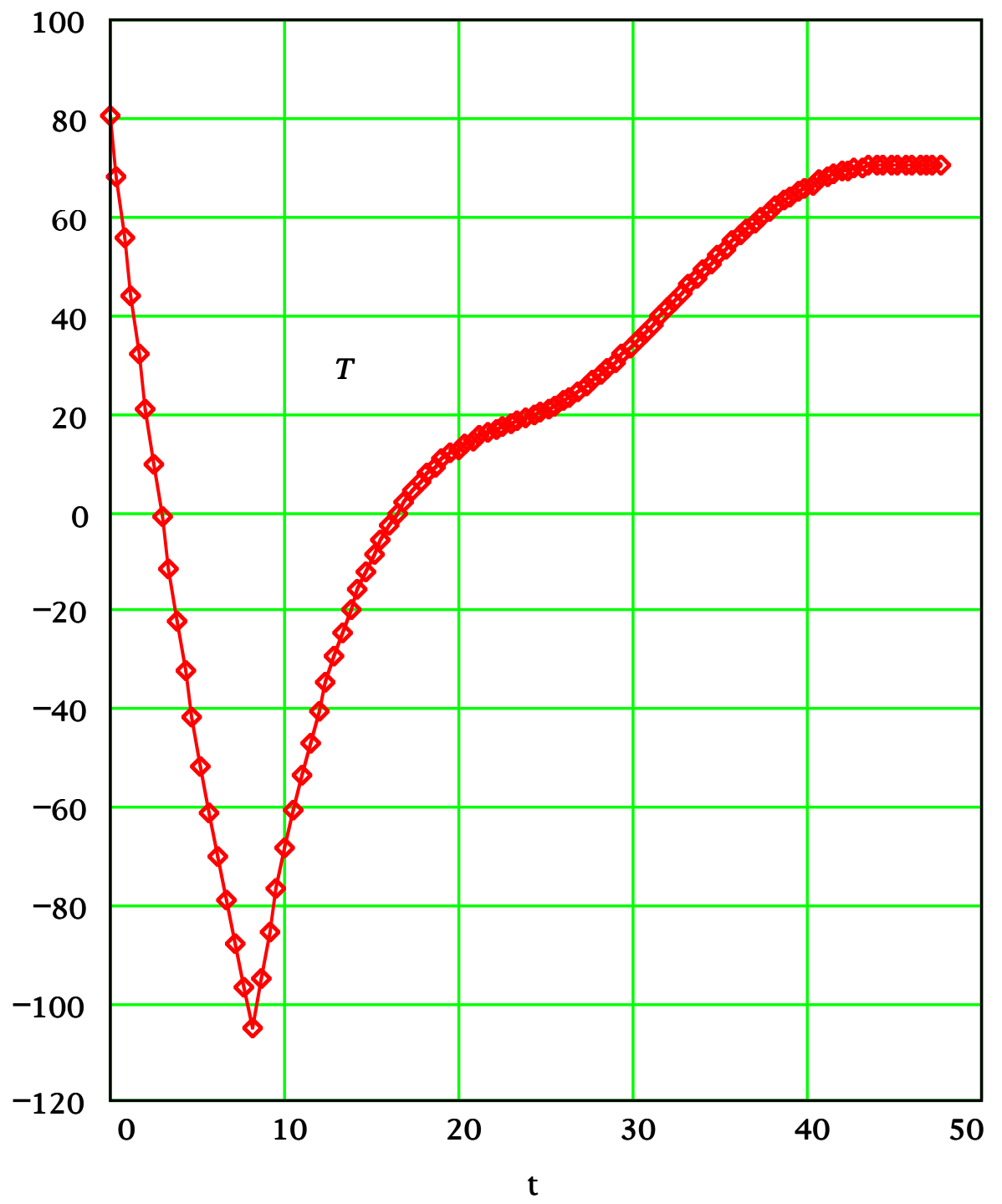

Figure 11, Temperature of tube gas ( $9 \mathrm{psi}),{ }^{\circ} \mathrm{F}$ 


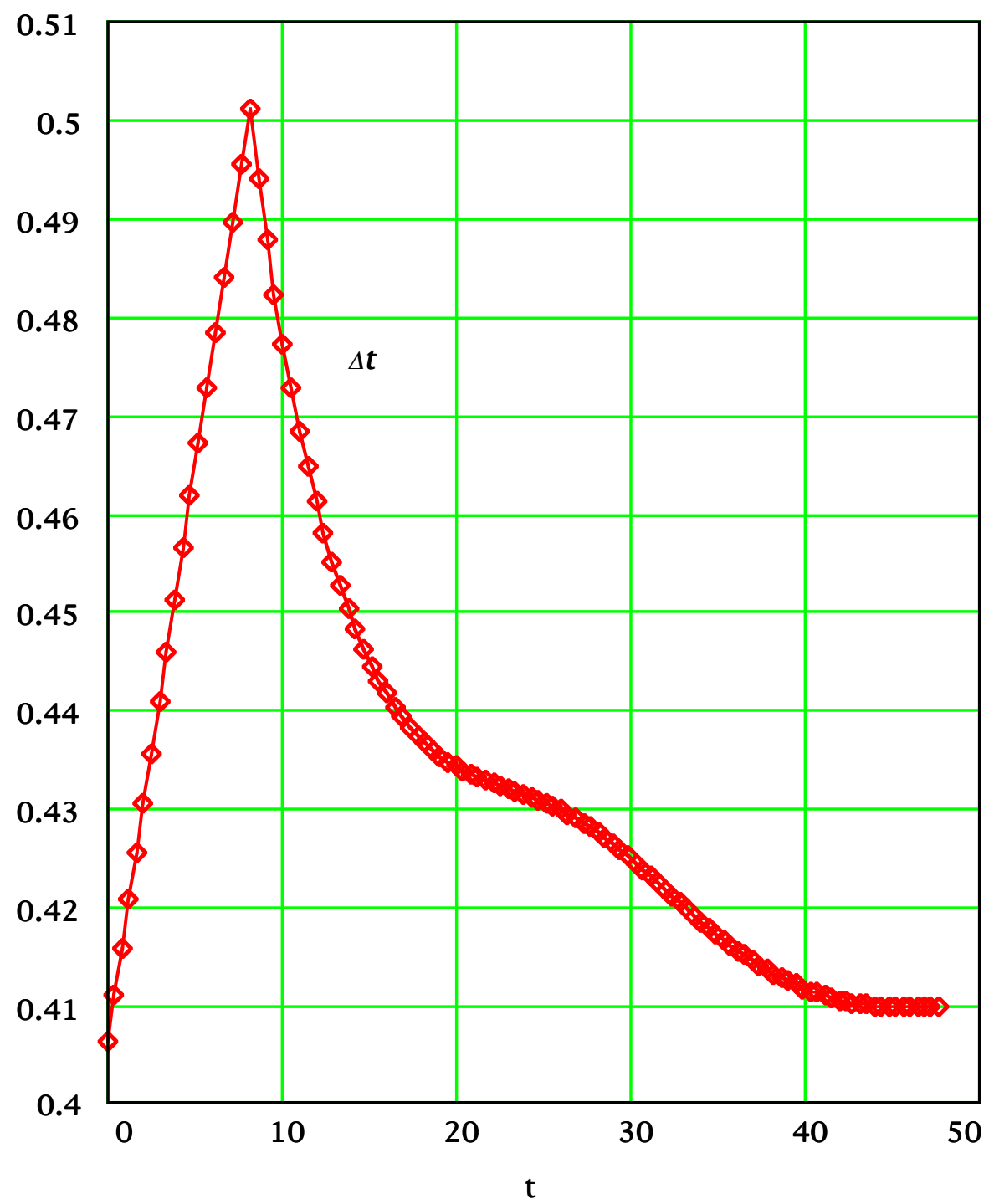

Figure 12 , Wave cycle time intervals (9 psi) 


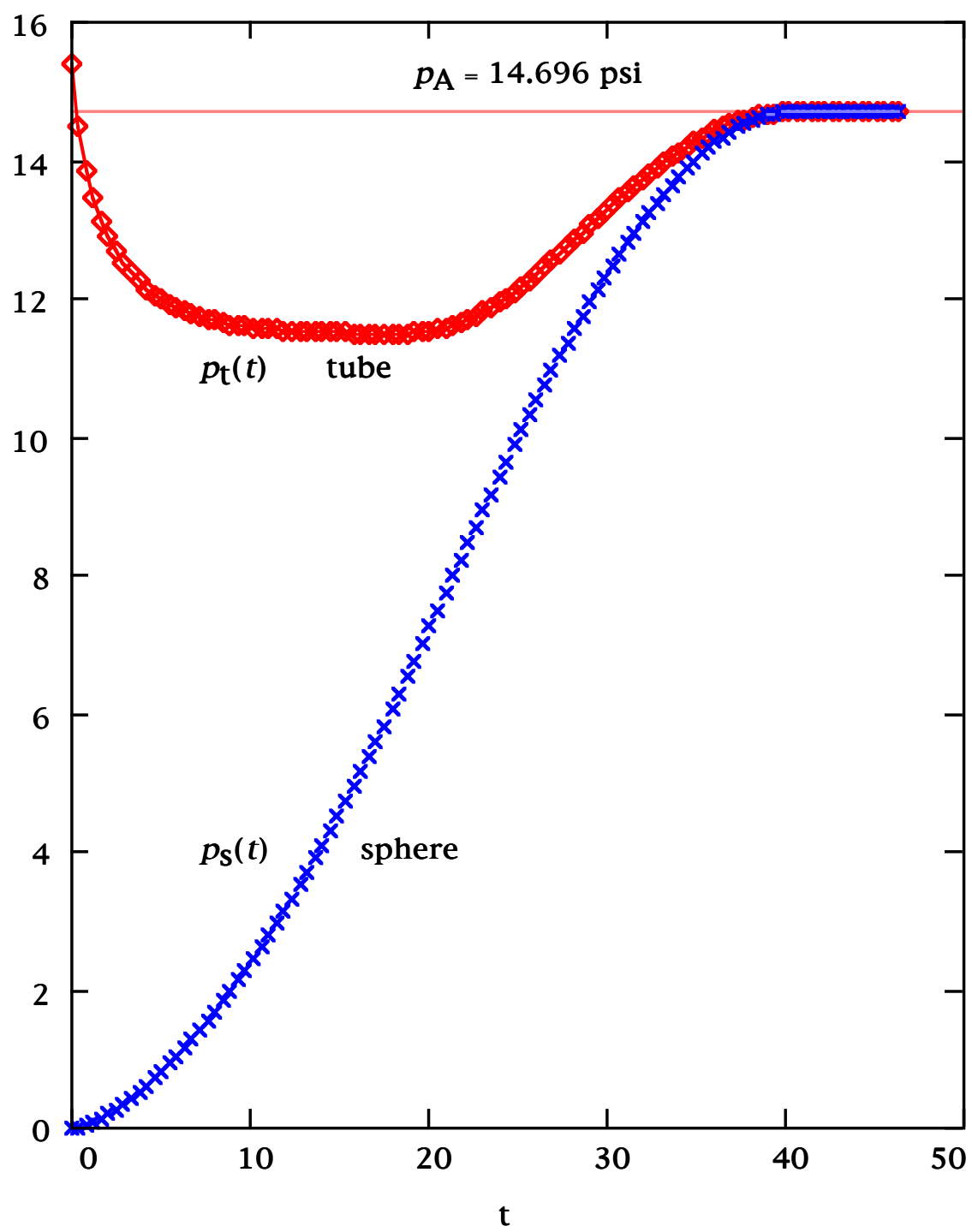

Figure 13, Pressure history with 0 psi leak trigger 


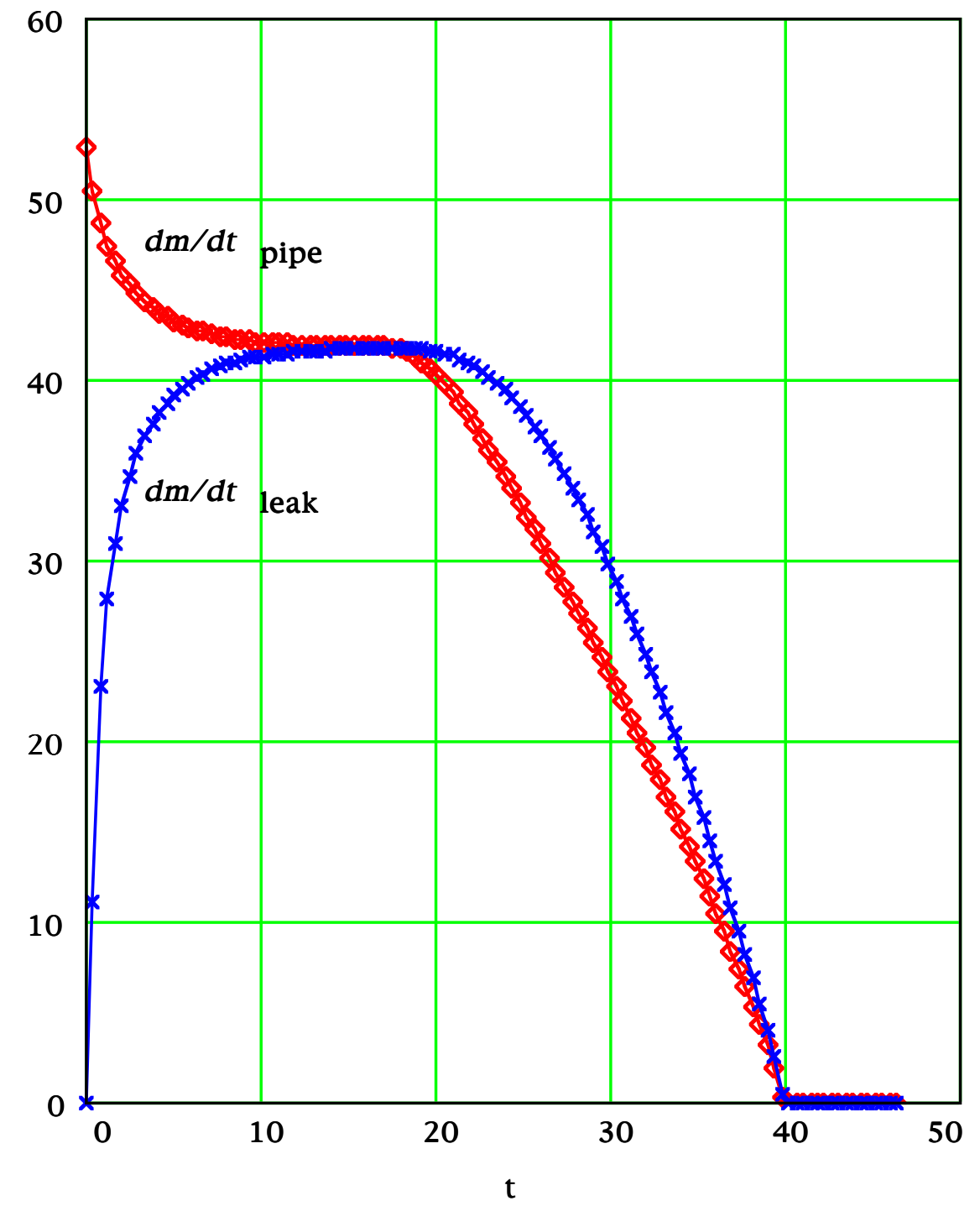

Figure 14, Mass flow rate history at $\Delta p=0$ psi 


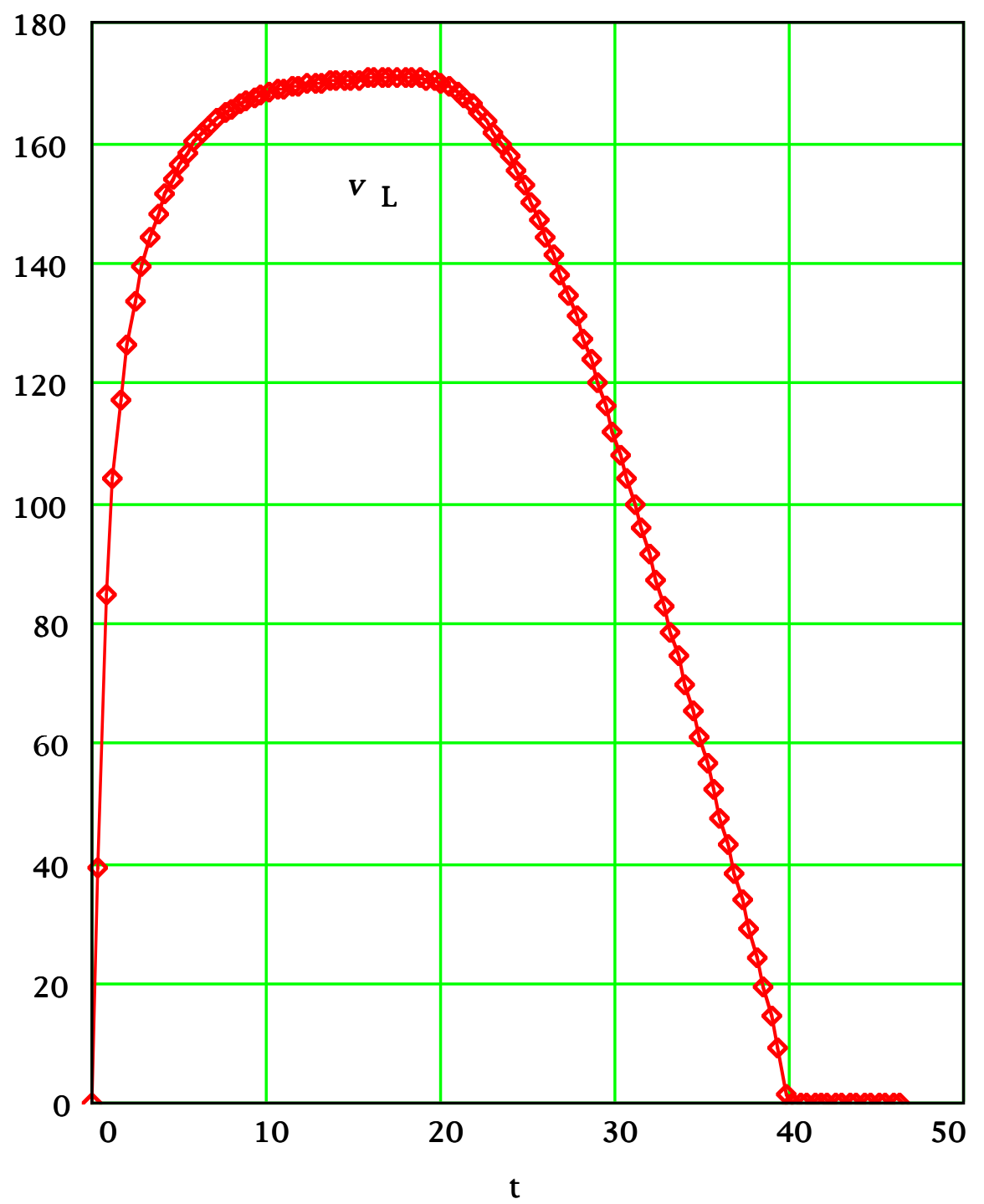

Figure 15, Velocity at the leak with 0 psi trigger 


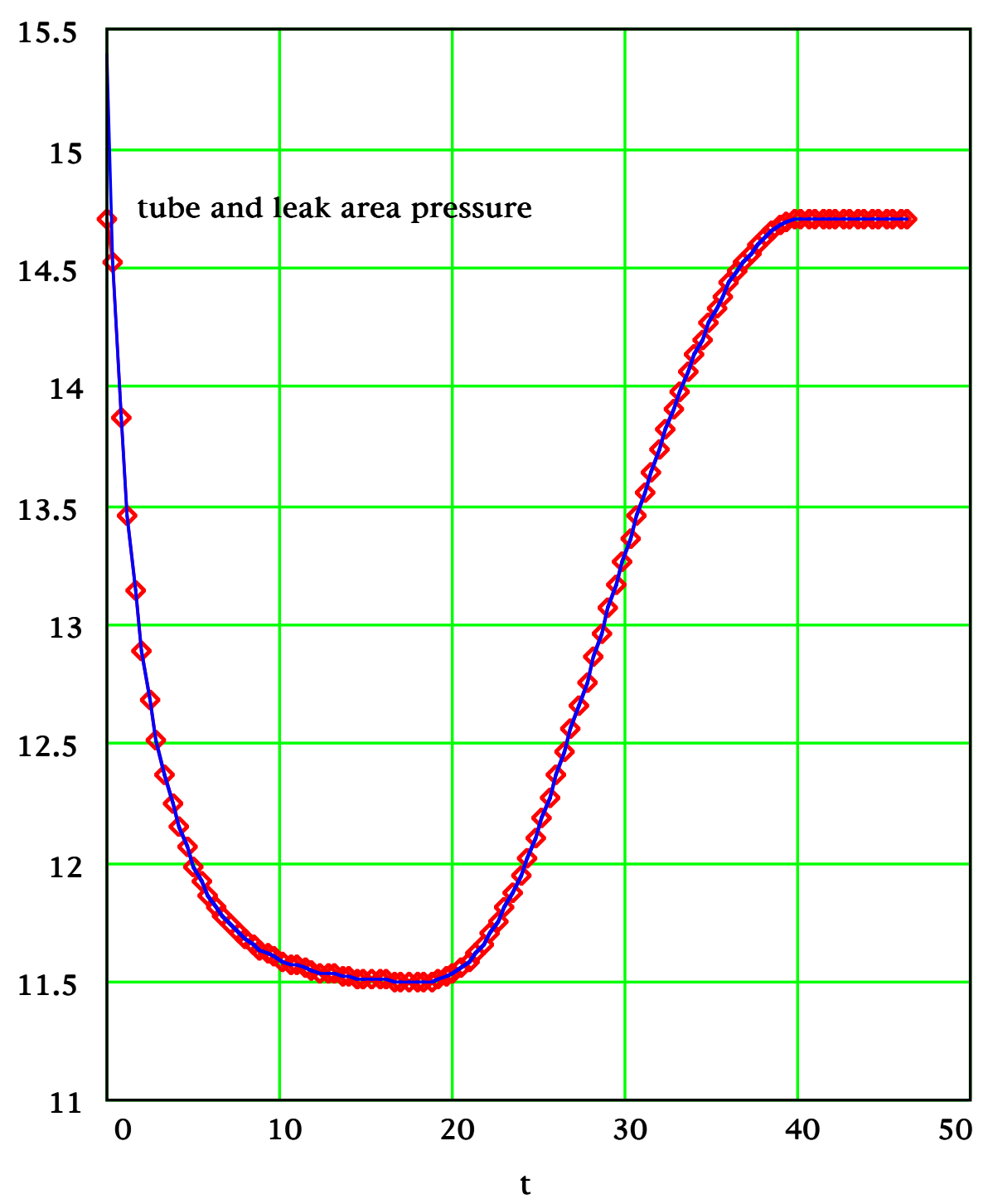

Figure 16, Leak and tube pressure history (0 psi) 


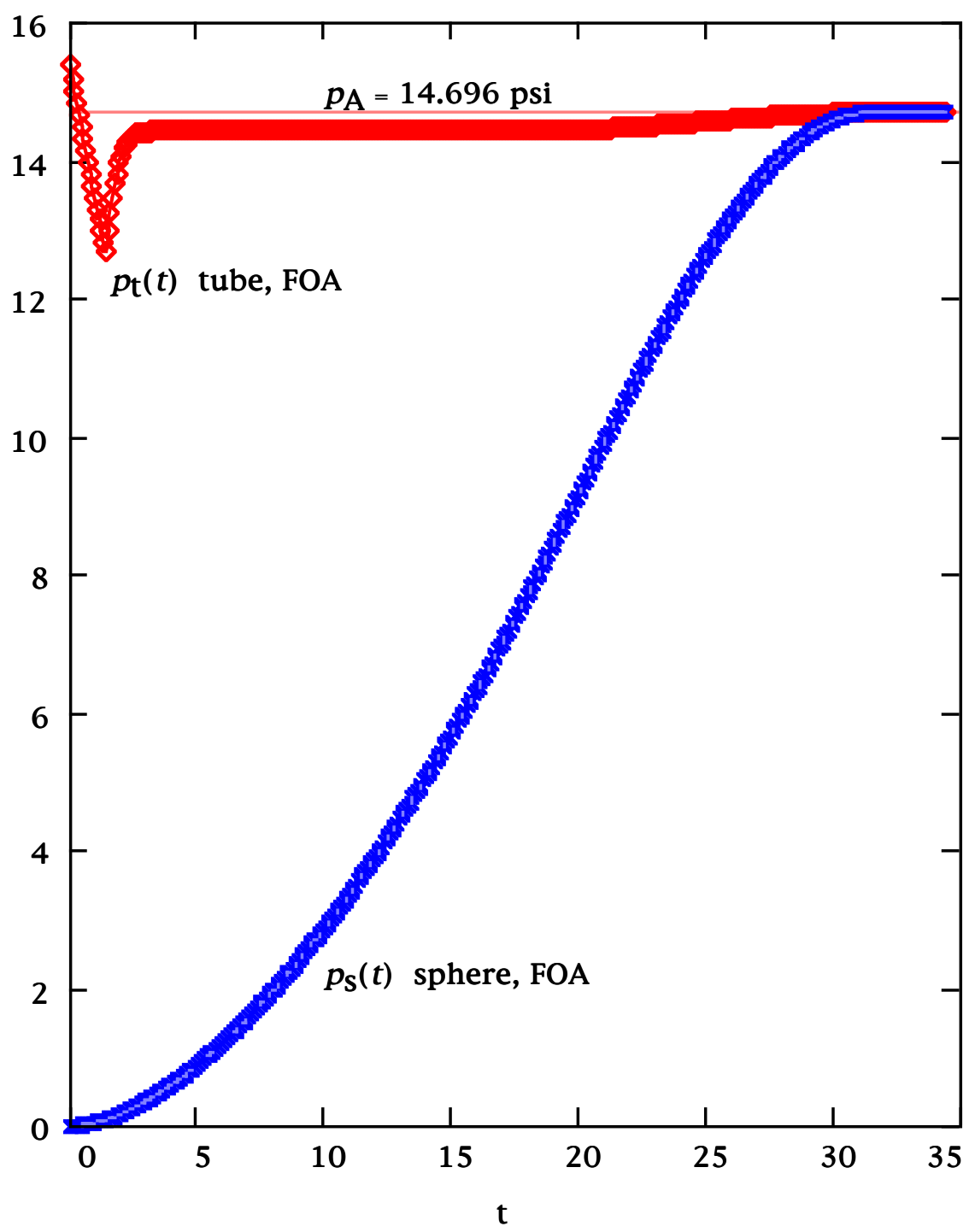

Figure 17, FOA pressure with $\Delta p=2$ psi 


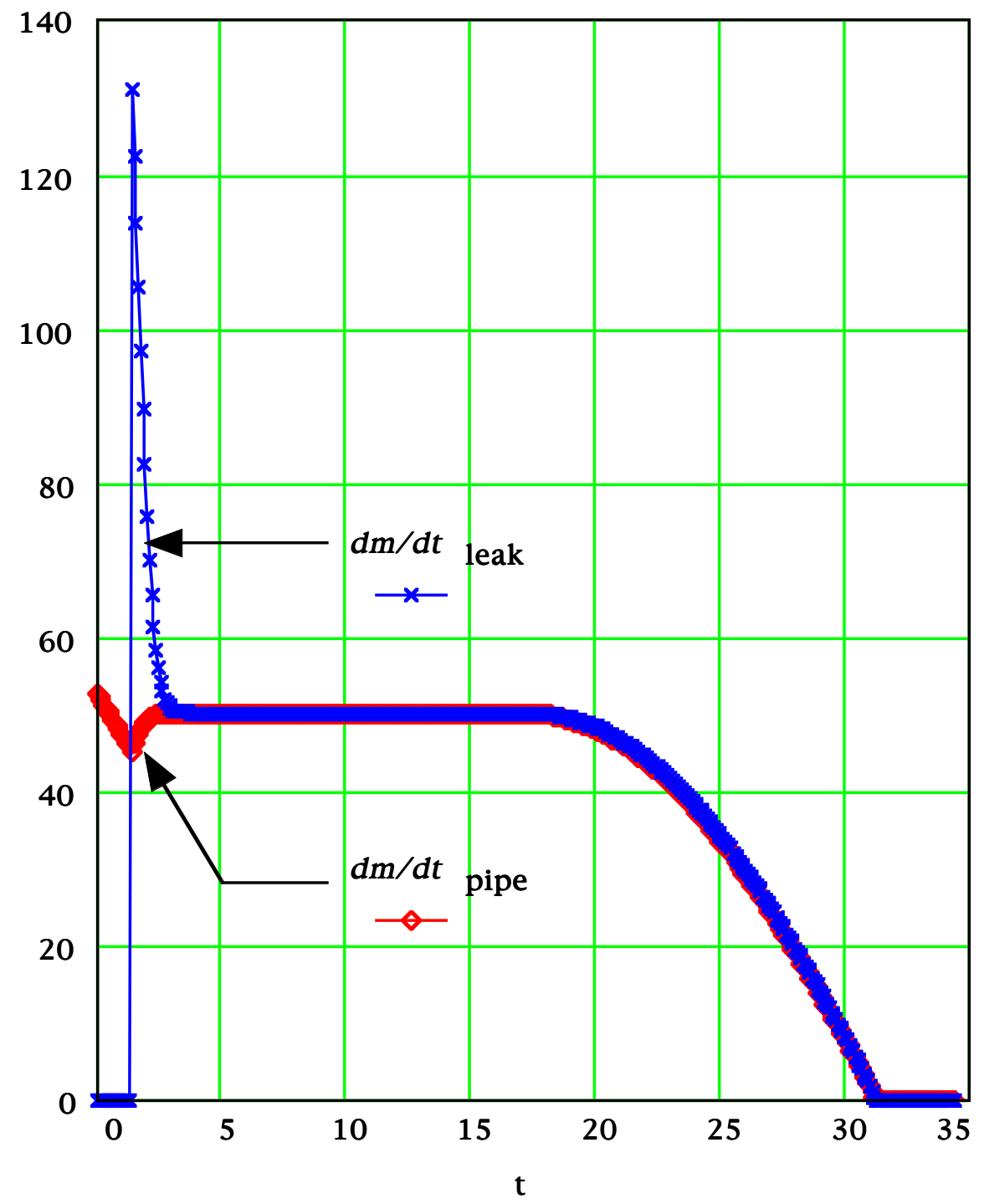

Figure 18, FOA mass flow rates with $\Delta p=2$ psi 


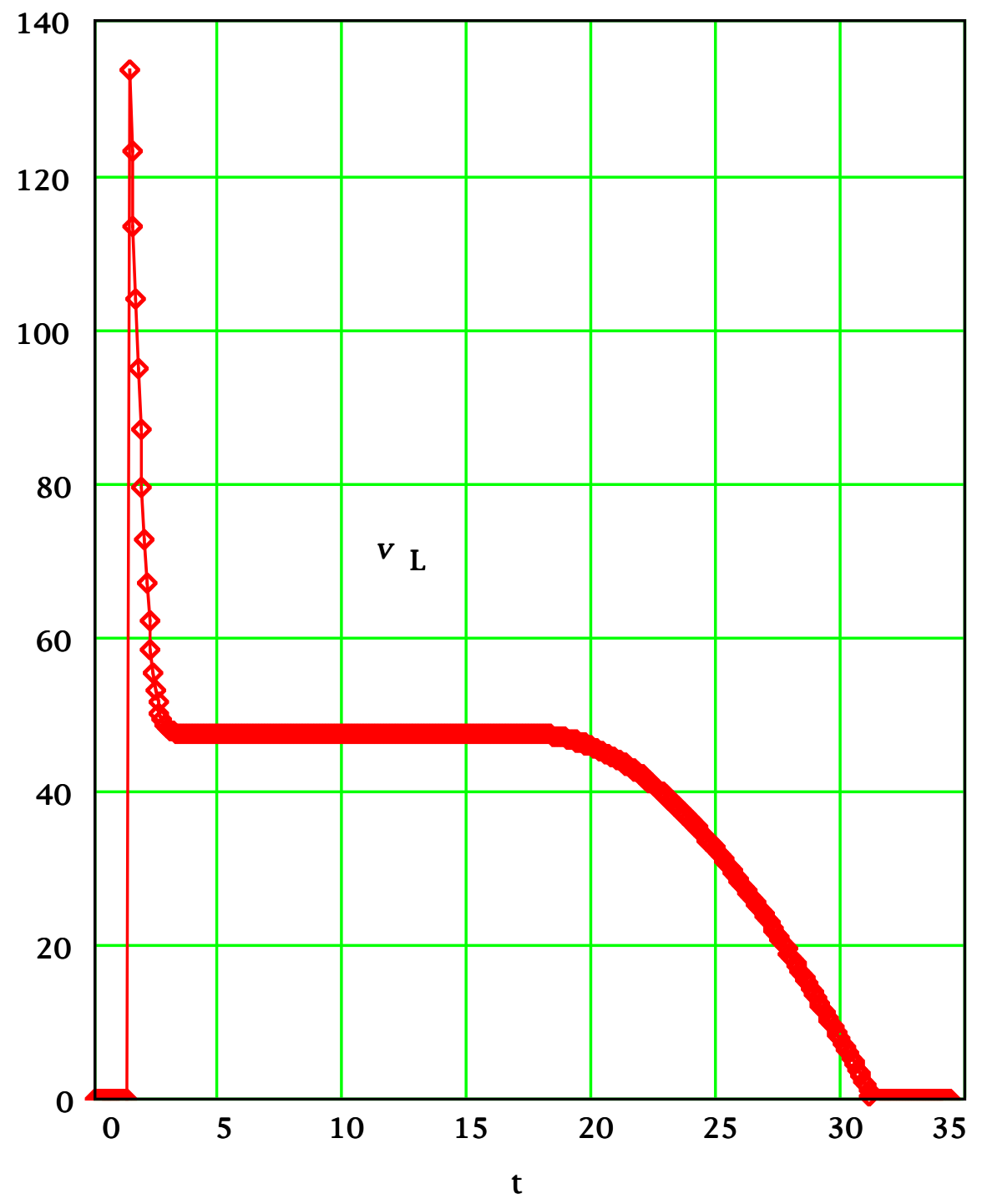

Figure 19, FOA leak velocity with $\Delta p=2$ psi 


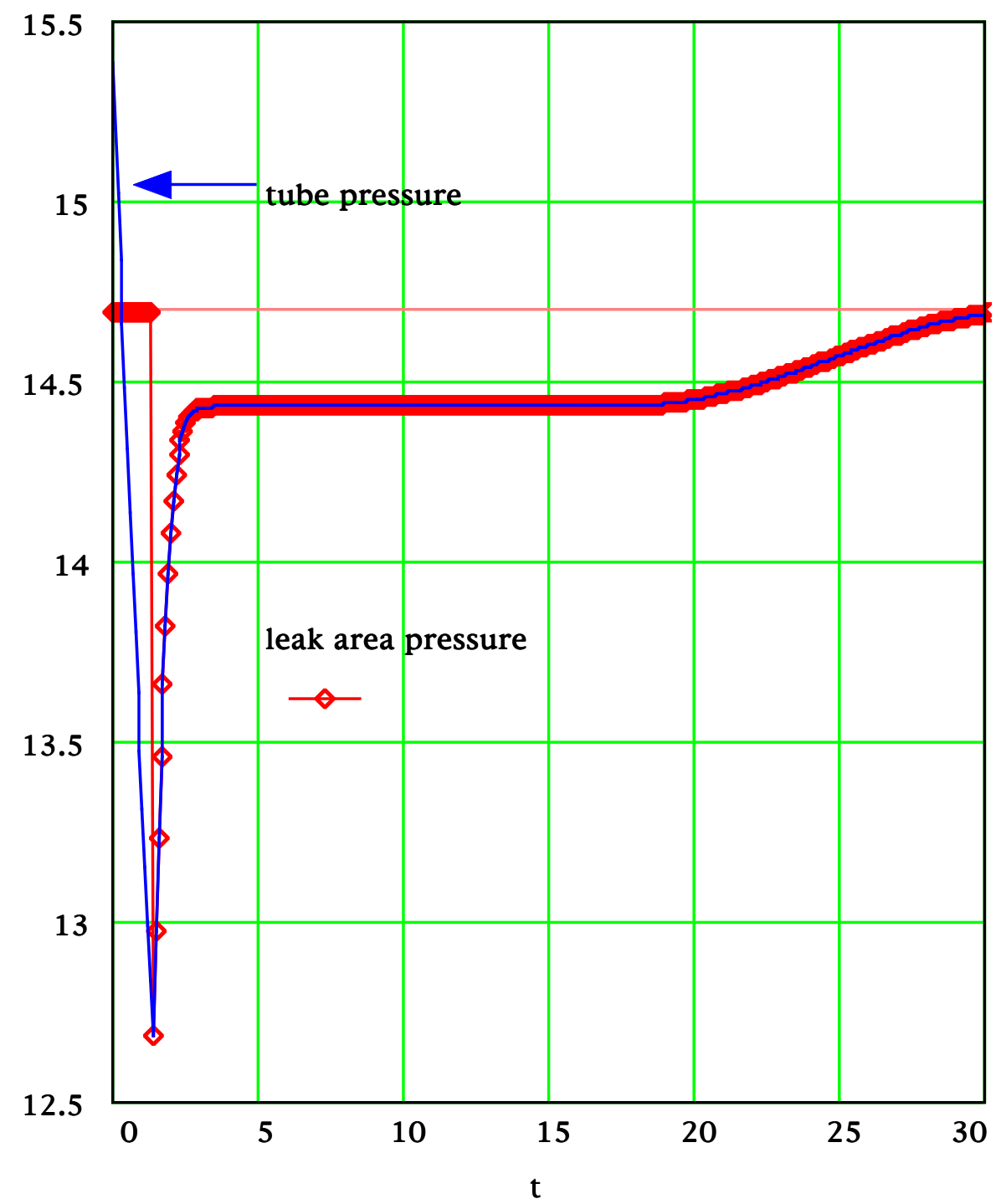

Figure 20, FOA leak area pressure with $\Delta p=2$ psi 